\title{
Reported oral and anal sex among adolescents and adults reporting heterosexual sex in sub-Saharan Africa: a systematic review
}

\author{
Imran O. Morhason-Bello ${ }^{1,2^{*}}$, Severin Kabakama ${ }^{3}$, Kathy Baisley ${ }^{4}$, Suzanna C. Francis ${ }^{4}$ and \\ Deborah Watson-Jones ${ }^{1,3}$
}

\begin{abstract}
Background: Oral and anal sexual behaviours are increasingly reported among adolescents and adults reporting heterosexual sex in peer-reviewed journals in high income countries, but less is known about these behaviours in low and middle-income countries, especially in sub-Saharan Africa. The aim of this systematic review is to describe the prevalence of, and motivations for, oral and anal sex among adolescents and adults reporting heterosexual sex in sub-Saharan Africa.
\end{abstract}

Methods: A systematic review of published articles that reported oral and or anal sex in sub-Saharan Africa was conducted from seven databases up to and including 30th August 2018.

Results: Of 13,592 articles, 103 met the inclusion criteria. The prevalence of reporting ever practising oral sex among adolescents, university students and a combined population of adolescents/adults ranged from 1.7-26.6\%, 5.0-46.4\% and 3.0-47.2\% respectively. Similarly, prevalences of reported ever practising anal sex ranged from $6.4-12.4 \%$ among adolescents, $0.3-46.5 \%$ among university students and $4.3-37.8 \%$ amongst combined population of adolescents and adults. Higher prevalences of oral and anal sex were reported among populations at high-risk for sexually transmitted infections and HIV and university students and, in most studies, both behaviours were more commonly reported by males than females. Heterosexual oral and anal sexual acts were associated with some high-risk behaviours such as inconsistent condom use and multiple sexual partners.

Conclusion: Reported oral and anal sex between men and women are prevalent behaviours in sub-Saharan Africa. Health professionals and policy makers should be aware of these behaviours and their potential associated health risks.

Keywords: Oral/anal sex, Sexual behaviour, Heterosexual, Adolescent, Adult, Sub-Saharan Africa

\section{Plain English summary}

Oral and anal sexual acts are increasingly reported in peer reviewed journals, especially among adolescents and young adults in high income countries. These behaviours are associated with negative health outcomes such as sexually transmitted infections (STIs). Oral and anal sex may be

\footnotetext{
* Correspondence: imranmorhasonbello@gmail.com

${ }^{1}$ Clinical Research Department, Faculty of Infectious and Tropical Diseases,

London School of Hygiene and Tropical Medicine, Keppel St, London WC1E 7HT, UK

2Obstetrics and Gynaecology Department, Faculty of Clinical Sciences,

College of Medicine, University of Ibadan, Ibadan, Nigeria

Full list of author information is available at the end of the article
}

important unrecognised modes of transmission for STIs, contributing to onward transmission. In addition, STIs in the oropharynx and anus may result in poor health outcomes such as oral and anal cancers; however, oral and anal sex are not always regarded as 'hetero-normative sexual intercourse', and are often disregarded by researchers, programmers and policy makers. Importantly, both sexual acts are sometimes perceived by some people to be safer than vaginal sex against pregnancy and STIs, and are associated with lower reported use of condoms to prevent HIV and STIs.

(c) The Author(s). 2019 Open Access This article is distributed under the terms of the Creative Commons Attribution 4.0 International License (http://creativecommons.org/licenses/by/4.0/), which permits unrestricted use, distribution, and 
We conducted a systematic review of published scientific papers reporting these behaviours in sub-Saharan Africa between 1946 and 30th August 2018. We investigated the prevalences of oral and anal sex, and factors that influenced these behaviours.

Our findings showed that oral and anal sex were commonly reported among adolescents and adults as well as female sex workers. We found that more boys/men reported oral and anal sex than girls/women in most of the studies, and that a substantial number of those engaging in oral and anal sex did not use barrier methods during those sexual acts.

In summary, oral and anal sexual behaviours are commonly reported in sub-Saharan Africa among people reporting heterosexual sex. While testing for oropharyngeal and anal infections may not be feasible in resource-constrained settings, these data are important for researchers, programmers and policy makers to raise awareness of these potential modes of STI transmission. Information about the risk of STI transmission for oral and anal sex should be included in information, education and counseling programmes for both general and key populations at risk for STIs.

\section{Background}

Condomless heterosexual oral and anal intercourse have been associated with extragenital sexually transmitted infections (STI) such as Chlamydia trachomatis, Neisseria gonorrhoea, syphilis, hepatitis, herpes simplex virus (HSV) and human papillomavirus (HPV) infections in the anal and oropharyngeal niches [1-6]. Although oral and anal STIs are frequently asymptomatic, they remain an important source of onward transmission $[1-3,5]$. Clinical sequelae of oral and anal STIs include pain, anal discharge, ulcerative proctitis, HPV-associated premalignant lesions and cancers [2, 3, 6, 7]. The comparative risk of HIV infection transmission between condomless anal sex and vaginal sex is higher than oral sex, and also, the risk is higher among those engaging in receptive anal sex than insertive anal sex when other HIV prevention methods such as anti-retroviral treatment or preexposure prophylaxis are not used $[8,9]$.

Several studies have reported a higher prevalence of oral and penile-anal sex among key affected populations' such as female sex workers (FSWs) $[10,11]$, men who have sex with men (MSM) [12], entertainment outlet workers, long distance drivers and people who inject drugs, compared to general populations [13]. Most studies report low or inconsistent condom use during oral and anal sex. For example, in Lima, Peru (2010), 98.4\% of FSWs aged 18-26 years had performed oral sex in their lifetime and only $20.0 \%$ reported condom use during the sexual act [11]. Another study in Peru (2013) showed that $21.2 \%$ of FSWs performed oral sex with clients in the previous month, and only $37.6 \%$ used condoms consistently while performing oral sex [14]. A study conducted in India (2009-2010) reported that $12.3 \%$ of $18-60$ year old FSWs engaged in receptive penile-anal intercourse in the past 6 months, and only $48.4 \%$ used condoms consistently [15]. In the Netherlands (2016), the prevalence of anal sex in the past 6 months among FSWs aged 18 years and above was $20.0 \%$, and only $31.0 \%$ of these FSWs always used condoms with clients [16]. In the USA, a systematic review of anal sex that included published articles between 1987 and 2013 reported that the prevalence of anal sex among FSWs ranged between 0 and $18.0 \%$ and that $14.0-82.0 \%$ of these FSWs always used condoms during anal sex [17].

Oral and anal sexual behaviours are increasingly reported among general population adolescents and adults reporting heterosexual sex in both developed and developing countries [18-21]. For example, a recent systematic review among young people aged less than 25 years worldwide showed that the average life time prevalence of reported heterosexual anal sex was $22.0 \%$, and this behaviour accounted for $3.0-24.0 \%$ of all reported sexual acts [22]. Three sexual behaviour surveys conducted between 1990 and 2012 among men and women aged 16-44 years in the United Kingdom showed that the prevalence of reported heterosexual penetrative anal sex by men in the past year increased from $7.0 \%$ in the $1990-1991$ survey to $12.2 \%$ in the 1999-2001 survey to $17.0 \%$ in $2010-2012$ [21]. Similarly, the proportion of women that reported any receptive anal sex in the past year also increased from 6.5 to $11.3 \%$ to $15.1 \%$ over the same periods [21]. Between the first and last surveys, the proportion of those giving or receiving oral sex in the preceding year increased from 65.6 to $75.0 \%$ among women and from 69.7 to $77.1 \%$ among men [21]. National surveys in Australia in 2001-2002 (aged 16-59 years) and 2012-2013 (aged 16-69 years) also showed a moderate increase in prevalence of reported oral and penile-anal sex over time in both genders $[18,23]$.

In sub-Saharan Africa (SSA), many studies reporting sexual behaviours in heterosexual relationships have focused on penile-vaginal sex and associated negative health outcomes [24-27]. This has influenced sexual health policies and programmes in many countries within the region $[28,29]$. The role of heterosexual oral and anal sexual acts within the spectrum of sexual behaviours needs to be documented within the region, in order to appreciate their potential impact on STI transmission and other associated morbidities such as oral and anal cancers. We conducted a systematic review of the prevalence of, and motivations for, practising heterosexual oral and penile-anal sex, and the cultural interpretations of these behaviours in SSA. 


\section{Methods}

This review was conducted in accordance with Preferred Items for Reporting of Systematic Reviews and Meta-analyses (PRISMA) and Meta-analysis of Observational Studies in Epidemiology (MOOSE) guidelines [30, 31]. The protocol was registered in PROSPERO database with registration number CRD42015025311 [32].

\section{Search strategy}

The search was conducted in English using seven databases: Medline; Embase; African-Wide Information; Cinahl; Global Health; Scopus; and Popline databases. We used medical subject headings $(\mathrm{MeSH})$ and text words related to oral and anal sex for the search. The terms used for oral sex were oral (sex OR sexual behaviour OR sexual practices), cunnilingus, oral vaginal contact, fellatio, oral penile contact, anilingus, and oral anal contact. The search terms for anal sex included anal (anus OR anal cavity) sex OR anal (sexual behaviour OR sexual practice) or anogenital (sex OR intercourse). The search was restricted to SSA by using "AND" before adding different search terms for sub-regions (West Africa OR East Africa OR Central Africa OR Southern Africa), and by specific country names. Multi-continent studies that had separate data from any country in SSA were also considered. The search included published articles from 1946 up to and including the final search of 30th August 2018. We also conducted manual searches of bibiliography of relevant publications on the subject. All titles retrieved from the search were compiled and reviewed with Endnote X 8.0 (Thompson Reuters) by one author (IMB); duplications were removed using the Endnote automated system and through a manual check.

\section{Eligibility criteria}

The eligibility criteria were determined apriori in the registered protocol [32], and only published original research articles that reported on oral or anal sex with a partner of the opposite sex in adolescents and adults in SSA were considered. The review excluded articles that focused exclusively on non-consensual heterosexual intercourse and MSM, even if men reported sex with both men and women. Commentaries or review articles, letter to editors, editorials, case series and case reports were also excluded. Oral sex was defined as oral contact with the vulva and or vagina (cunnilingus) or penile shaft (fellatio) or anus (analingus). Anal sex was defined as penetration (insertion) of a man's penis into the woman's anus or, for women, reception of the penile shaft into the the woman's anus.

Two authors (IMB, SK) independently screened the titles and abstracts using the eligibility criteria. Thereafter, full-text of selected articles were independently reviewed again by IMB and SK. Discrepancies at each stage of review were resolved through discussion and consensus. DWJ and SCF served as arbitrators for cases that could not be resolved by discussion.

\section{Data extraction}

Data were extracted by IMB into pre-specified data extraction form prepared in Microsoft Excel 2010, and verified by SK. The data extracted included author and journals' name, sampling methods, study location, definition of oral and anal sex, prevalence/proportion of those that reported oral and anal sex, including reasons/motivations and risk factors associated with these behaviours. Prevalence was defined as the proportion of those that reported oral/anal sex by the total number of individuals in the study population.

For reporting periods, studies that used "ever had" or "ever experienced" or "life-time experience" for oral and or anal sex were classified as "ever practiced". Other specific look back reporting periods recorded were "past 12 months", "past 3 months", "past 1 month", "last sexual act" and the "first sexual act". We classified studies that used any form of random sampling as "probability sampling" while others that used non-probability techniques were categorised as "convenience" or "snowball" or "venue-based" or "volunteer" sampling. Studies that had participants with increased risk of STI were categorised as key affected populations (e.g. FSWs, HIV positive men and women, recreational facility workers such as bar and guesthouse workers, long distance truck drivers and participants described as "high-risk" in the methods sections of eligible publications).

\section{Assessment of quality of eligible studies}

Separate risk of bias tools were used to assess the quality of papers reporting quantitative and qualitative data. For papers reporting quantitative data, a validated tool for observational studies was modified (Additional file 1: Figure S3) [33] by developing a list of methodological features of the eligible studies that could bias the prevalence and risk factor estimates for oral and anal sex. For each study, we assessed documentation of the following items to classify the study as being either at lower or higher risk of bias: description of study population (Yes/No); type of sampling techniques (probability sampling [Yes] or non-probability sampling/not reported [No]); response rate (Yes/No); eligibility criteria (Yes/No); definition of oral sex (Yes/No); definition of anal sex (Yes/No); sexual behaviour roles reported as giving/insertive or receptive/received (Yes/No); risk factor estimates controlled for potential confounders (Yes/No); and inclusion of a statement on the ethical approval (Yes/No). For papers reporting qualitative data, a critical appraisal skill programme tool was used for qualitative studies (Additional file 1: Figure S4) [34]. Each tool has ten fields for assessment; studies with five or more "Yes" fields were considered to be of lower risk of bias. 


\section{Data synthesis}

Due to the heterogeneity in study populations, study design, sampling strategy and definitions of exposure of interest in the eligible studies, we performed a descriptive analysis of both quantitative and qualitative studies without providing a pooled estimates by meta-analysis. In the descriptive analysis, data were disaggregated by exposure of interest (oral sex, anal sex or both), gender, population category (key affected or general population), country locations and regions. We presented prevalences of outcomes (oral and anal sex) and risk factors for oral and anal sex in quantitative studies. We also used Minitab 18.0 statistical software (Minitab, Inc.) to graphically present individual value plot of prevalences of oral and anal sex by sub-region, study population, population category and risk of bias to visualise the range in prevalences compared by population type, geographical area and risk of bias. Key findings from qualitative studies were summarised and categorised into the following themes: cultural meaning; interpretations; and reported personal experiences.

\section{Results}

Out of the 13,592 articles retrieved, 155 full texts were reviewed and 103 were included in the descriptive analysis of heterosexual oral and or anal sexual behaviours (Fig. 1). Among the 103 articles reviewed, 38 reported on both oral and anal sex [35-73], 53 reported on anal sex only [74$125]$, and 12 reported on oral sex only [126-137]. One Nigerian publication out of the 38 articles reported the prevalence of oral and anal sex as a combined outcome [43]. Six articles were mixed method studies (a study each from Ethiopia, Kenya, Nigeria, Tanzania, Zambia and another was conducted in Kenya and Rwanda) [39, 66, 70, 90, 120, 133]. Fifty-nine studies were from Southern Africa, 38 were from East Africa, 20 were from West Africa and four were from Central Africa (Additional file 2: Table S1).

Only nine quantitative studies presented the operational definitions of reported oral sex [37, 38, 52, 54, 66, 71-73, 137] and six studies presented operational definitions of reported anal sex $[38,52,54,66,73,90]$ in the methods section of the papers. For oral sex, definitions included oral stimulation of either the external female genitalia (i.e. clitoris, vulva and vagina) or the penis [37]; ejaculation during oral stimulation of the male genitalia [38]; contact between the mouth and penis or vagina or anus [54]; and putting one's mouth on their partner's penis or vagina or letting their partner put his or her mouth on one's penis or vagina [52]. For anal sex, definitions included were ejaculation during anal sex [38]; introduction of the penis into the anus or back passage of the partner [54, 66, 73, 90]; and putting the penis into the partner's anus or letting the partner insert his penis to her anus [52].

Twelve out of 13 articles presented qualitative data investigating motivations, cultural interpretations and personal experiences of anal sex [66, 90, 100-104, 120, 122-125] (Table 1). Of these, seven studies (two from South Africa [100, 101] and three from Tanzania [103, $104,124]$, and two multi-country studies conducted in Kenya, Tanzania and Uganda [102] and Uganda, South Africa and Zimbabwe [123]) used qualitative methods only. Six qualitative studies each on anal sex were conducted among key affected populations [90, 102-104, 124, 133] and general populations [66, 100, 101, 120, 122, 123]. No studies included adolescents. One article reported on perception of FSWs on the use of condom for oral sex [133].

The majority of the studies (90 out of 103) focused on participants aged 10 to 49 years (Additional file 2: Table S1). Eleven out of 91 studies included only adolescents (aged $\leq 19$ years) [40, 46-48, 54-56, 127]. Seven studies did not indicate the study population age [35, 81, 100-102]. Overall, 46 studies included both male and females [35, 37-48, 51-56, 59, 64-66, 68, 70, 73, 78, 80, 84, 87, 92, 94, $101,102,111,114,120,126-129,134,136], 51$ studies included women/girls only $[36,49,50,57,58,60-63,67$, 69, 71, 72, 74, 76, 77, 79, 81-83, 85-91, 96-99, 105, 106, 109, 110, 112, 113, 115-119, 121, 132, 133, 135], and eight studies included men/boys only [75, 93, 95, 107, 108, 130, 131, 137].

\section{Reported condom use during heterosexual oral and anal sex}

Condom use was reported in 19 studies during heterosexual anal sex $[38,39,52,53,56,59,61,62,73,75,77,79$, $84,87,90,106,112,113,115,120]$, five studies during oral sex $[38,52,53,56,61]$, and 29 studies for combined vaginal, oral and anal sexual experience $[40,47,54,57,58,60$, 62, 63, 65, 67-69, 76, 80, 82, 85, 88, 92, 97, 98, 105, 107, 111, 116-119, 135]. (Additional file 2: Table S2).

Four (three from South Africa and one from East Africa) out of six studies that reported condomless anal sex were among key affected populations [53, 77, 87, 90], and one study was a general population study in South Africa [77]. Condomless oral sex was also reported in a study among HIV positive men and women in South Africa [53]. Reported condom use tended to be higher during heterosexual anal sex than during oral sex, and was more frequently reported among key affected populations than general populations during heterosexual anal sex. The range of any condom use during oral sex was $1.7-16.5 \%$ among three general population studies $[38,52,56]$. Of these, consistent condom use during oral sex was reported by $13.2 \%$ of Nigerian and $16.5 \%$ of Zimbabwean students [38], and by $12.2 \%$ of high school students in Ethiopia [52]. A study in South Africa showed that $54.8 \%$ of FSWs reported consistent condom use during oral sex [61].

The range of any condom use during heterosexual anal sex was $6.7-73.1 \%$ among eight general population studies $[38,39,52,56,59,73,77,120]$. Consistent condom 


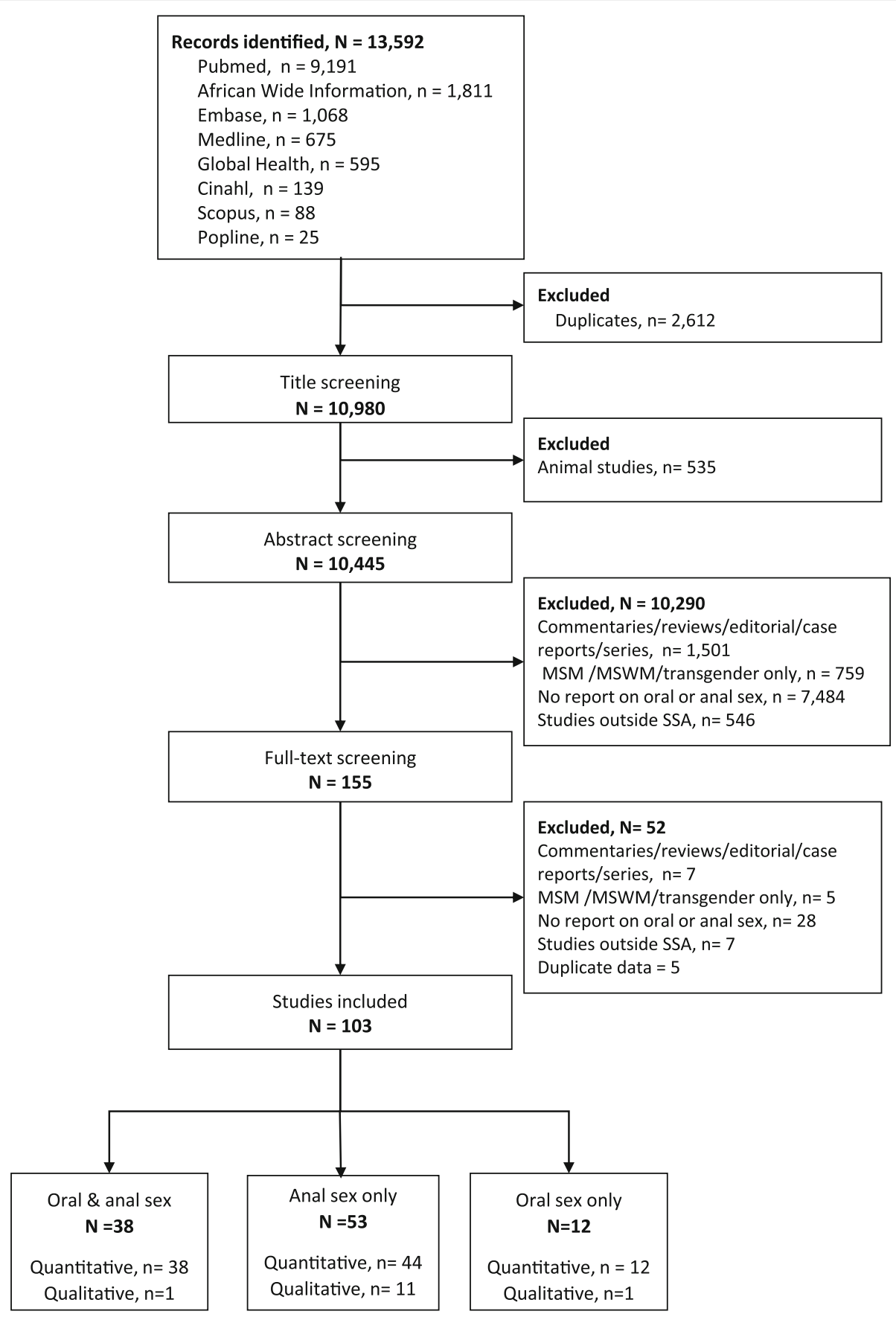

Fig. 1 PRISMA Flow for the systematic review

use during anal sex was reported by 22.5 and $27.5 \%$ of Nigerian and Zimbabwean students respectively [38], 26.1\% of Ethiopian high school students [52] and $36.4 \%$ of adolescents and young adults in Tanzania [120]. Among five key affected population studies, the range of condom use during heterosexual anal sex was $13.2 .0-67.0 \%[61,75,79,84,112]$. Two of these studies reported consistent condom use of $45.0 \%$ among Kenyan FSWs with their clients [79] and 50\% among HIV positive women in a South African city [61]. The range of condomless heterosexual anal sex among four key affected population studies was 7.0$54.3 \%[53,79,87,90]$.

\section{Prevalence of reported oral sex}

Only six (two from South Africa and one each from Nigeria, Rwanda, Zambia and Zimbabwe) out of the 51 oral sex studies described the prevalence of reported oral sex as 


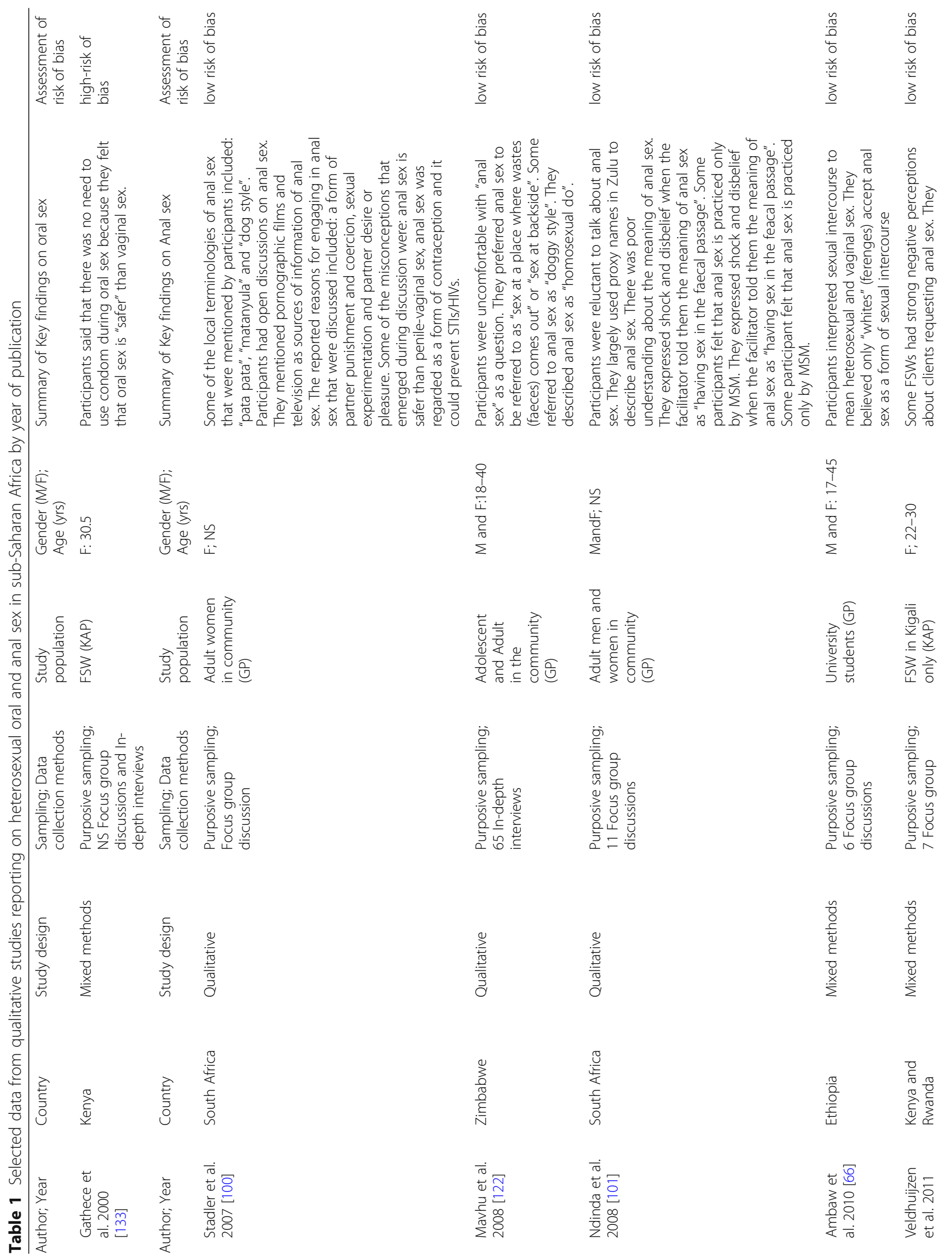




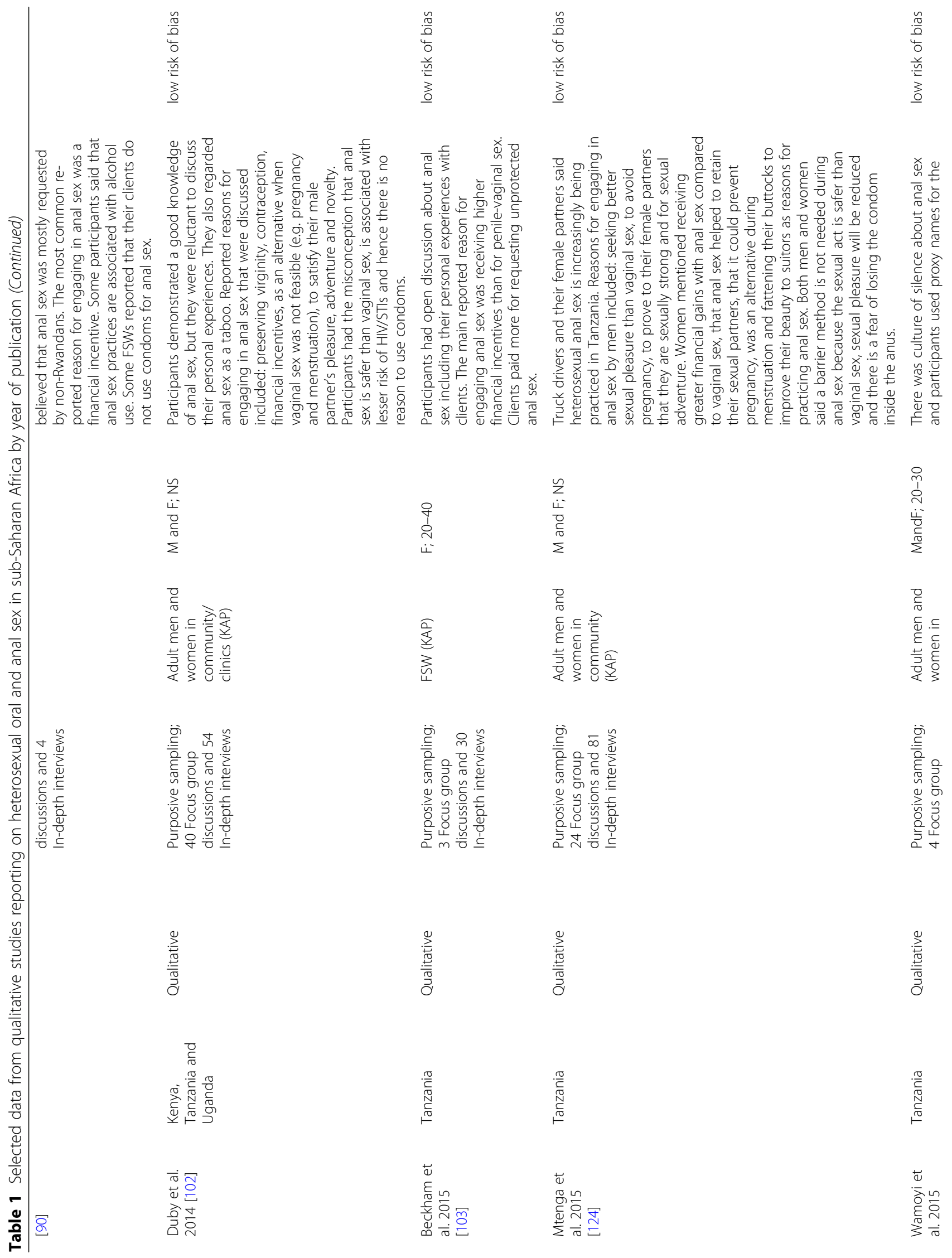




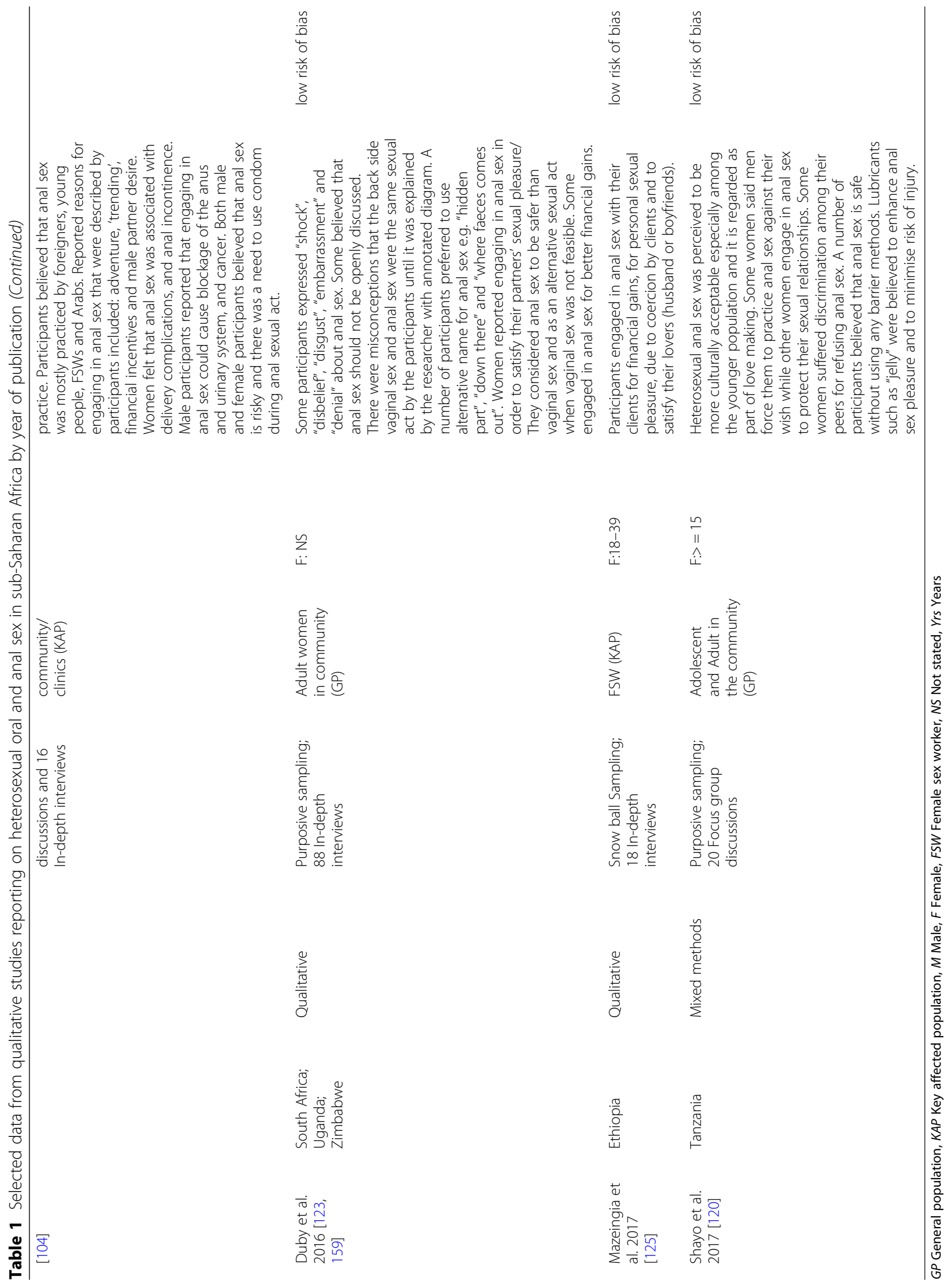




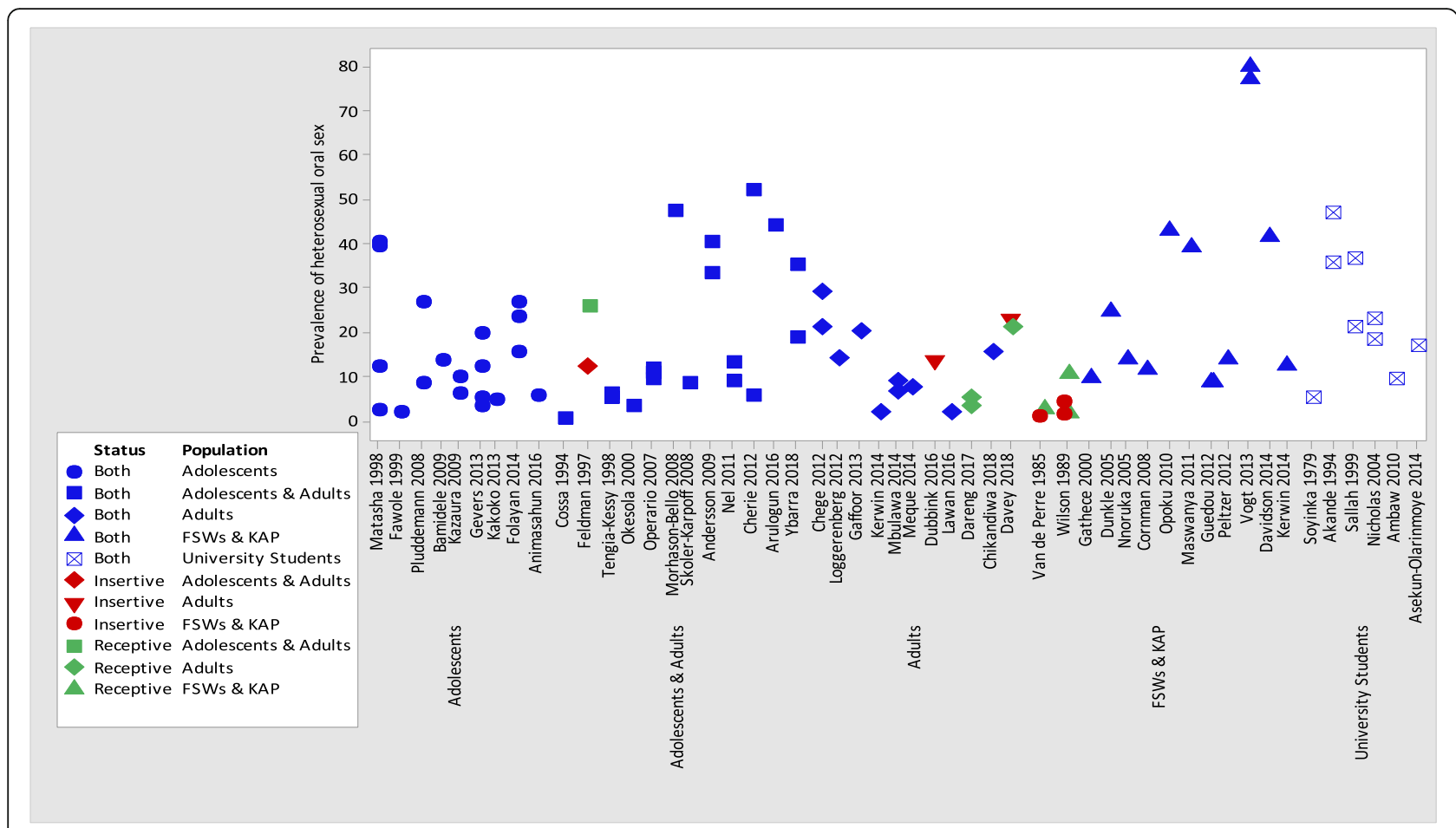

Fig. 2 Prevalence of oral sex by study population

either giving or receiving oral sex [36, 37, 39, 69, 71, 72]. Most studies that reported on prevalence of oral sex were from South African region, among adolescents and young adults, and key affected populations (Fig. 2, Additional file 2: Table S1 and Additional file 1: Figures S1 and S2).

\section{Reported prevalence of ever practiced oral sex}

Twenty-eight general population studies reported on the prevalence of ever practising oral sex (Table 1), of which only two studies (Nigeria and Zambia) described the prevalence of giving and receiving oral sex separately $[39,71]$. However, the Zambian study combined these data by gender [39]. Of the remaining 26 general population studies reporting oral sex prevalence, 14 described this by gender: five among adolescents and adults [50, 63, 65, 73, 126]; four among adolescents [46, 48, 54, 135]; two studies among adult women [60, 132]; two studies among university students [41, 66]; and one study among an adult men only [130]. Men/boys tended to report a higher prevalence of ever practising oral sex compared to women/girls across these populations. For example, $26.2 \%$ of boys reported ever practising oral sex compared to $8.1 \%$ of girls in a cross-sectional study in South Africa [46], and 22.8\% of males reported ever practising oral sex compared to $18.2 \%$ of female South African university students [41]. The range of reported oral sex prevalence in the remaining studies was $5.0-46.4 \%$ among university students [35, 38, 64, 68]; $1.7-26.6 \%$ among adolescents [47, 55, 56, 127]; 3.0-47.2\% among a combined population of adolescents and adults $[45,52$, $128,136]$, and $1.7-40.8 \%$ in three studies among adult populations [130-132]. In all but adult populations, higher prevalences of ever practicing oral sex were recorded after 2000 compared to before 2000. Studies conducted among university students reported a relatively higher prevalence of oral sex compared with other groups within the general population.

Ten studies amongst key affected populations described prevalence of ever practising oral sex [36, 42, 49, 57, 61, 70, 129, 131, 133, 137]. Three studies were among FSWs, of which only a Rwandan study described prevalence of giving and receiving oral sex separately $[36,57,133]$. The Rwandan study showed that 1.8 and $0.5 \%$ of FSWs reported that they ever received or gave oral sex respectively [36]. Prevalence of ever practiced oral sex in the other two studies among FSWs were 9.0\% in Kenya [133] and 24.1\% in South Africa [57]. The prevalences of ever practiced oral sex in two Nigerian studies were reported to be $1.5 \%$ among adult men and women in the general community [70] and 13.3\% among HIV positive men and women [42]. In Ghana, $42.3 \%$ of 'women considered to be at risk of STIs' (working in food and recreational facilities) ever practiced oral sex [49]. Three studies from South Africa reported prevalences of ever practising oral sex among key affected population [61, 129, 137]. A study showed that higher proportion of HIV positive men $(79.4 \%)$ in 
the community/clinic reported ever practising oral sex than HIV positive women (76.5\%) [129] while the two other studies reported prevalences of ever practiced oral sex of 13.9\% [57] among HIV positive women [61] and $15.0 \%$ among HIV positive adult men [137] in the community.

\section{Prevalence of oral sex by other reporting periods}

Data on the prevalence of oral sex using other reporting periods came from 11 general population studies [40, 51, $52,54,56,58,59,62,69,72,134]$. Three of these studies found that men/boys generally reported a higher prevalence of oral sex than in women/girls. For example, any oral sex in the past 3 months was reported by 29.0 and $21.0 \%$ of 18-34year old Kenyan men and women respectively [51], and by 4.8 and $2.8 \%$ of $12-15$ year old South African boys and girls respectively [54]. In contrast, a Tanzanian study showed that having had oral sex during their first sexual experience was reported by 39.0 and $40.0 \%$ of primary school boys and girls, respectively [40]. Among a combined population of adolescents and adults in Addis Ababa, the prevalence of reported oral sex in the past 12 months among the $5.4 \%$ of the study population that had ever practiced oral sex was 51.6\% [52]. Two South African studies reported the prevalence of oral sex in the past 3 months as $8.0 \%$ among girls/ women above 16 years [58] and 19.9\% among women aged 18 years and above [62]. Reported prevalence of oral sex in the past 6 months ranged between 32.9 and $40.0 \%$ among adult men and women with their casual and steady partners, respectively in Soweto [59], 13.4\% among women in rural Mopani District [69], and 6.2\% of men and $8.7 \%$ of women in Cape Town [134]. Finally, 22.8 and $21.0 \%$ of pregnant and postpartum women in Cape Town described either giving or receiving oral sex in the past 12 months respectively respectively [72].

Among four key affected population studies, two studies among HIV positive men and women described the prevalence of reported oral sex in the past 3 months to be $11.0 \%$ in KwaZulu-Natal and $13.4 \%$ in Mpumalanga in South Africa [44, 53]. A third study among FSWs and their clients in Harare, Zimbabwe, described higher reporting by men of receiving oral sex from FSWs during their last sexual act than by FSWs giving oral sex during their last sexual encounters $(10.0 \%$ vs $1.0 \%)$ [37]. In the same study, 4.0 and $1.0 \%$ of men and FSWs respectively reported giving/receiving oral sex during their last sexual act [37]. Another study among FSWs from South Africa, Uganda and Benin reported that the prevalence of oral sex in the past month with clients was 8.3\% [67].

\section{Factors associated with engaging in oral sex}

Eight studies investigated factors associated with reported oral sex (Table 2). Five of these studies reported unadjusted estimates [48, 51, 54, 56, 133]. In 2000, a study in Kenya found that older FSWs were less likely to have ever engaged in oral sex than younger FSW [133]. In 2012, another study in Kenya, showed that men tended to report oral sex in the past 3 months more than women (29.0\% vs $21.0 \%)$ [51]. Similarly, adolescent boys in Tanzania were more likely to report ever practicing oral sex compared with adolescent girls $(9.4 \%$ vs $5.8 \%)$ [48]. In Nigeria, girls were more likely to report oral sex as their last sexual act compared with boys (23.5\% vs $15.1 \%)$ [56]. Girls in South Africa aged 12-15 years who were "currently dating" compared to girls that were not currently dating were more likely to have reported ever having oral sex with their partners $(8.1 \%$ versus $0.6 \%)$ and also having oral sex in the last 3 months (6.5\% versus $0 \%$, ) [54]. Similar results on dating status were also reported among boys $(20.2 \%$ versus 8.1\%) [54].

Two studies from Ethiopia and a study from Malawi reported adjusted estimates for the association between potential risk factors and reported oral sex [52, 66, 131]. A study among 3543 adolescents in high schools in Ethiopia showed that reporting oral sex was associated with having an illiterate mother, being younger (15-16 years compared to 17 years and older), being female, having a perception of oral sexual activity in peers, having a positive attitude to oral sex and low self-esteem [52]. Of the $5.4 \%$ who reported ever having had oral sex, $13.5 \%$ had initiated oral sex before the age of 10 years [52]. Another Ethiopian study found that ever practising oral sex among university students was associated with male gender; being a first year undergraduate; being a student in faculties of business and economics, technology, humanities social sciences and education; living off campus; being Protestant Christian denomination; and having boy/girl friends [66]. A study among Malawian men that reported ever practicing oral sex had three times odds of ever using condoms, two times odds of spending money in the last 3 months and having higher number of lifetime sexual partners than men with no history of oral sex [131].

\section{Motivations for engaging in oral sex}

Only one study reported on motivations for engaging in oral sex. This study was conducted among Ethiopian school boys and girls aged 15-24 years in Addis Ababa [52]. The main motivations reported by participants were preventing pregnancy (95.9\%), minimizing risk of HIV acquisition (86.5\%), preserving virginity $(85.8 \%)$ and reducing the risk of STIs $(80.4 \%)$. Of those having oral sex within the past 12 months, $48.0 \%$ had received a gift in exchange for practising oral sex. 


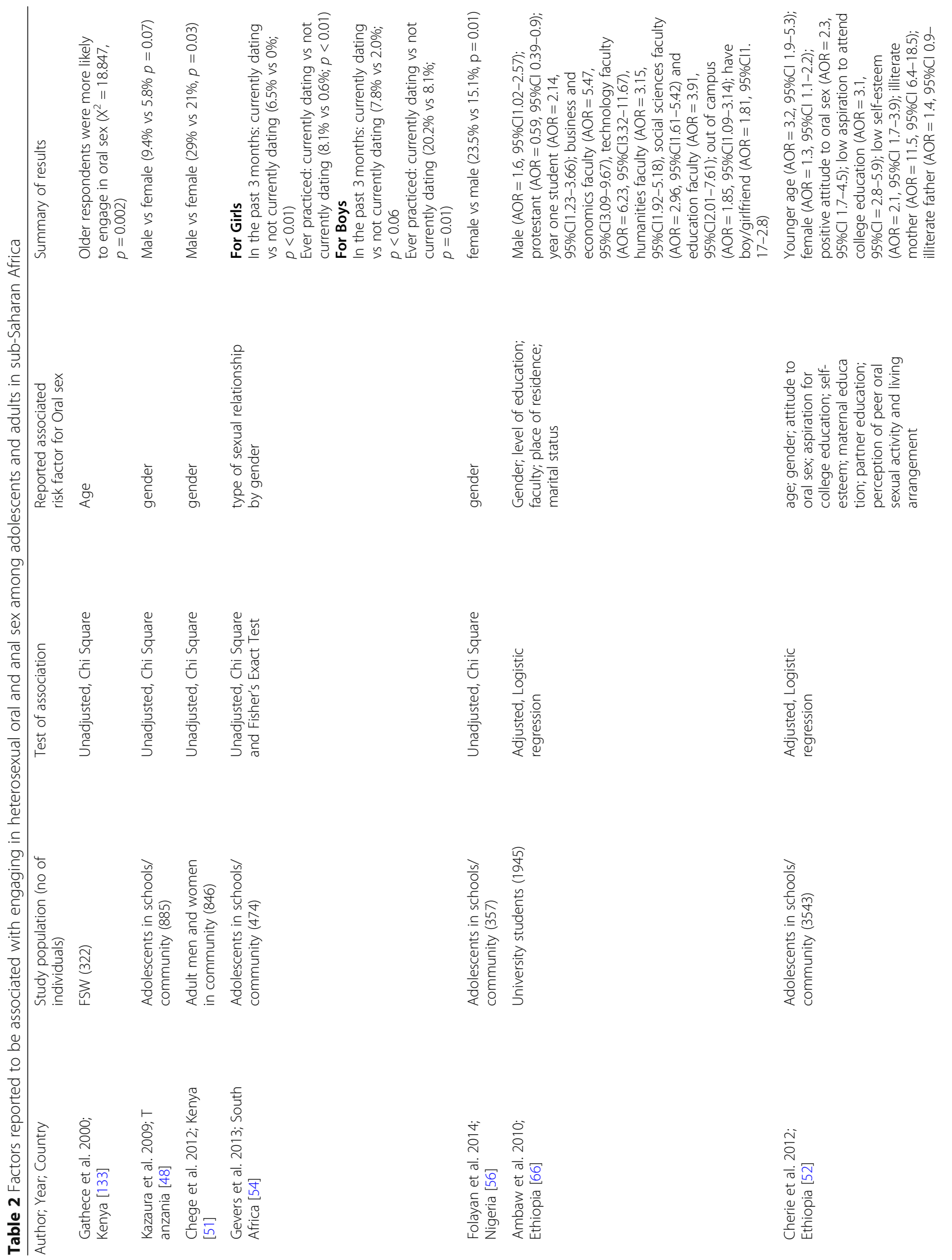




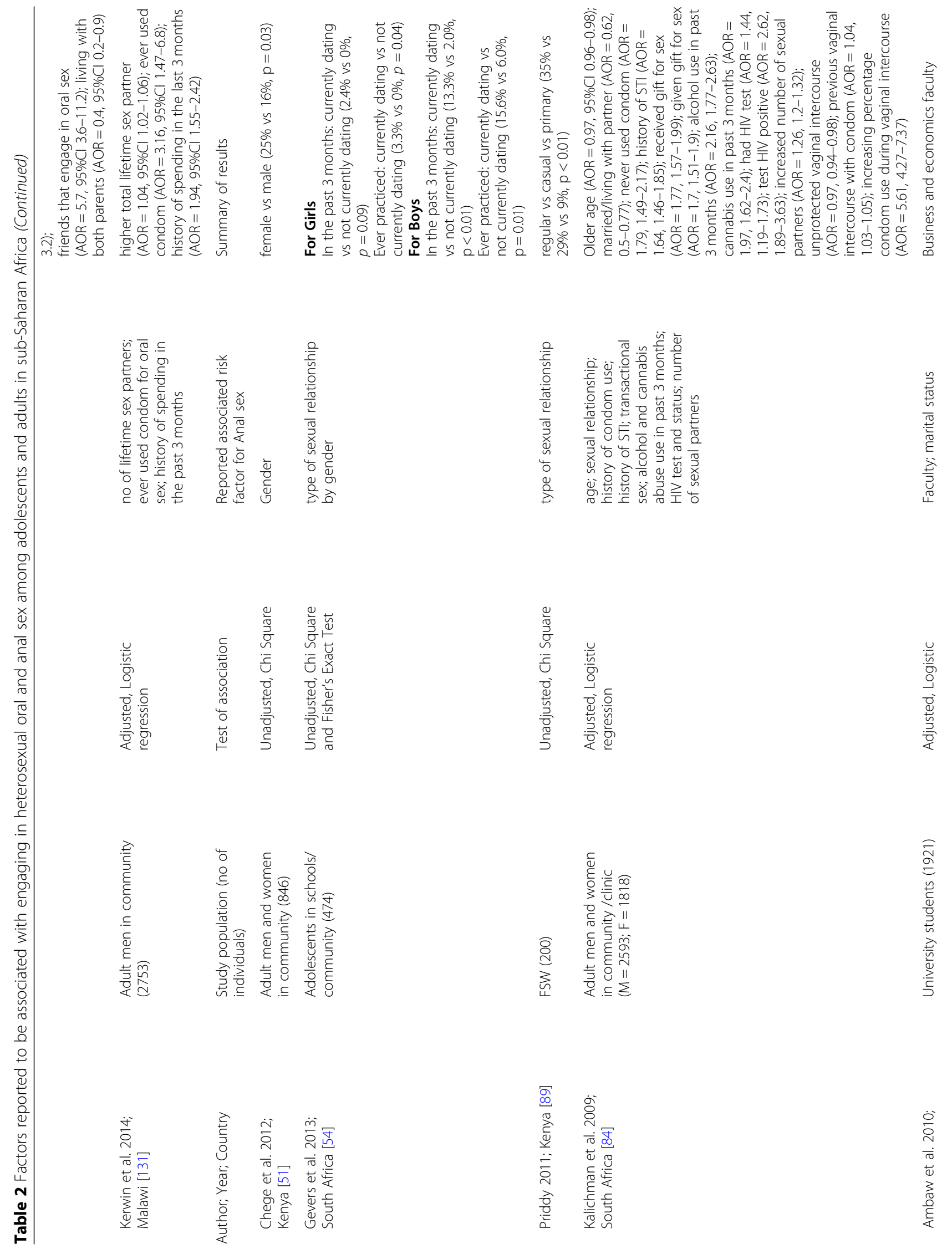


Morhason-Bello et al. Reproductive Health

(2019) $16: 48$

Page 13 of 23

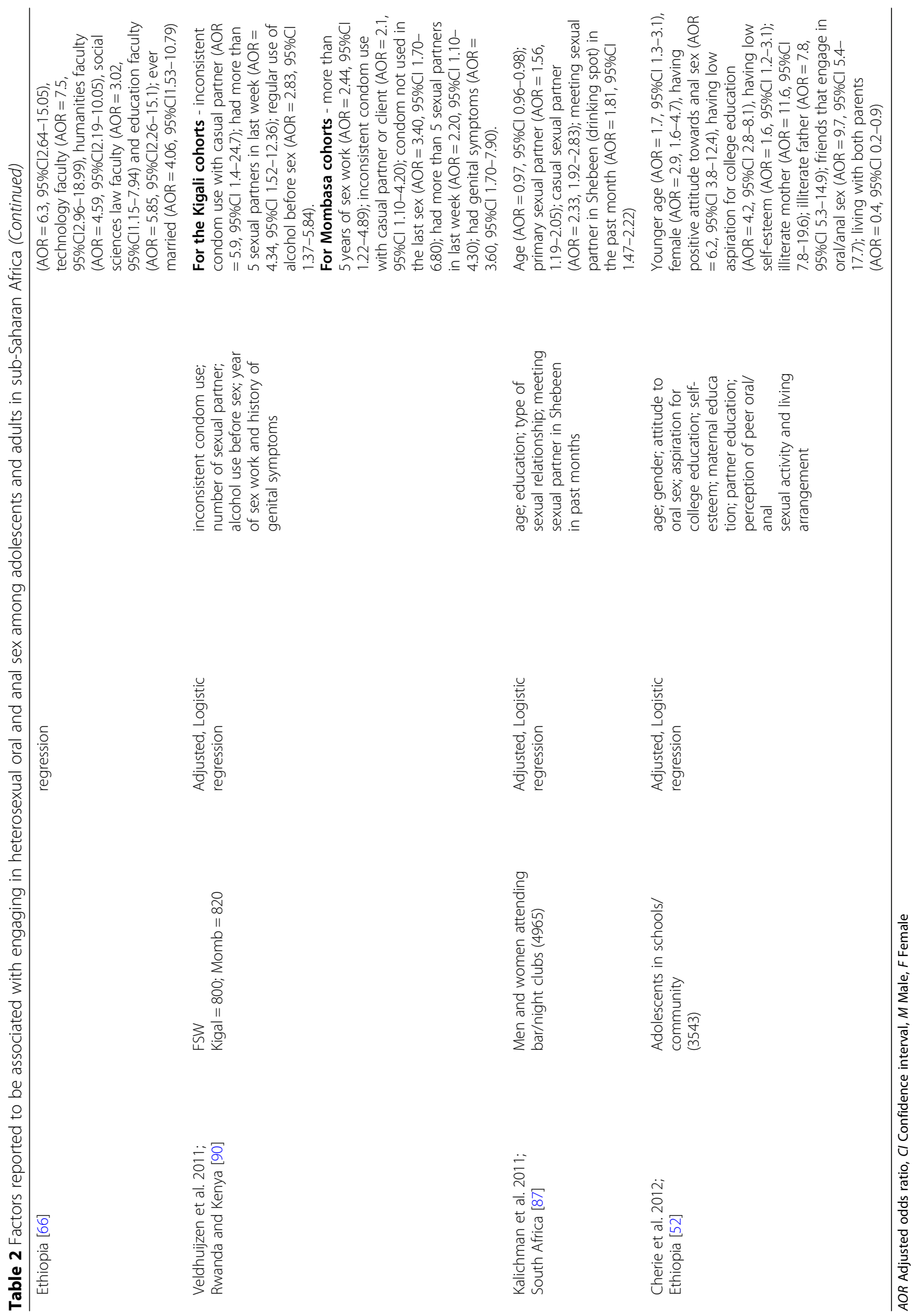




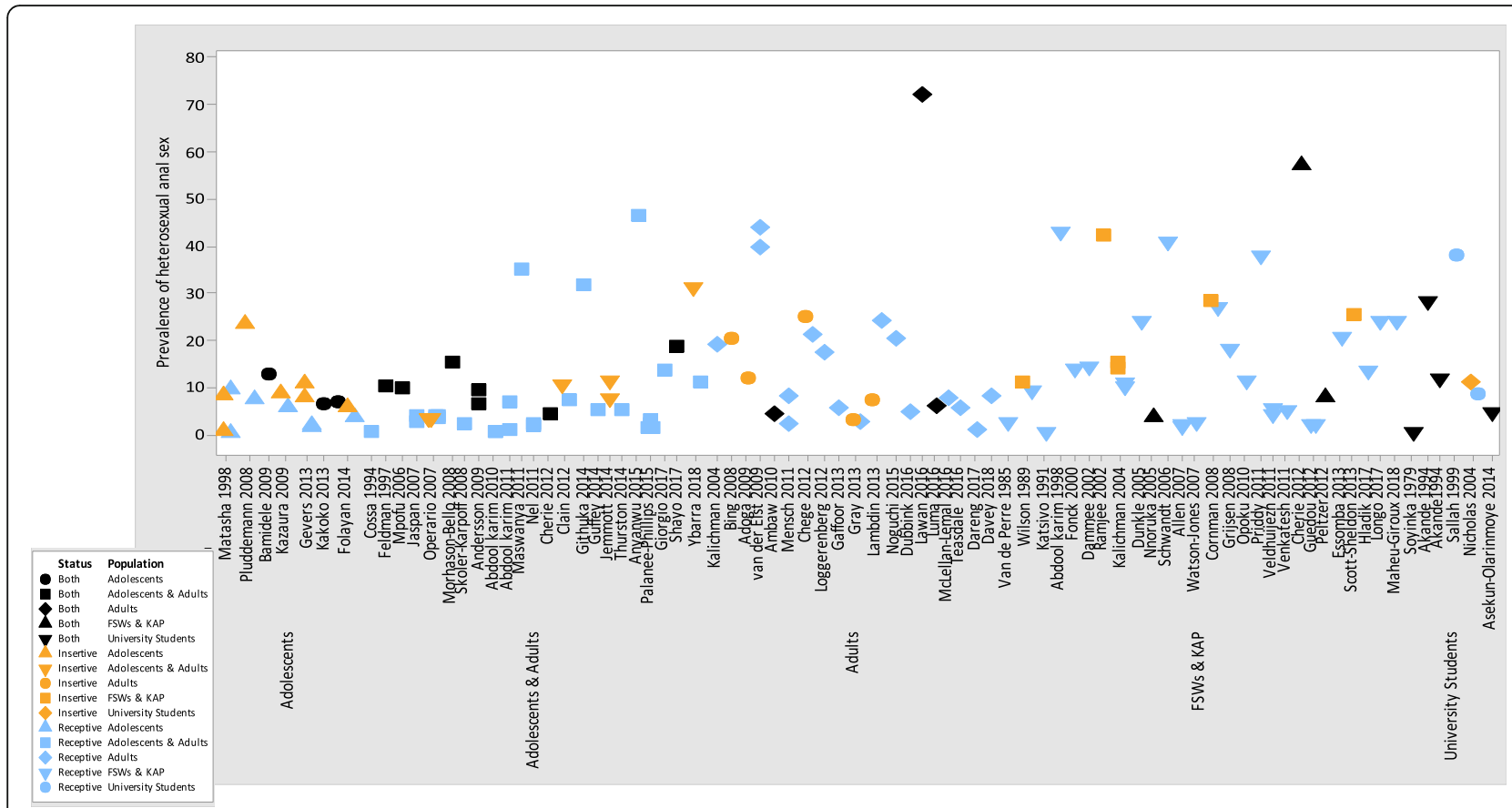

Fig. 3 Prevalence of heterosexual anal sex by study population

\section{Prevalence of reported heterosexual anal sex}

Sixty-five out of 82 studies distinguished the prevalence of reported anal sex into 'insertive' by male participants or 'receptive' by female participants [36, 37, 40, 41, 44, $46,48-51,54,56-58,60-67,69,71-77,79-99,105-$ 113, 115-119, 121]. Most studies that described anal sex were from Southern and East African countries, among adolescents and young adults, and key affected populations (Fig. 3, Additional file 2: Table S1 and Additional file 1: Figures S4 and S5). We used the same reporting periods as oral sex in presenting prevalences of heterosexual anal sex in different populations.

Reported prevalence of ever practiced heterosexual anal sex Fifty-one out of 82 studies reported on the prevalence of ever practising heterosexual anal sex. Twenty-three out of 51 studies were conducted among key affected populations $[36,42,49,57,61,70,74-76,79,82,89,93,105-108,110$, $112,114,117,118]$. Seventeen of the 28 general population studies described reported prevalence of receptive or insertive heterosexual anal sex separately $[41,46,48,50,54,60$, 63-66, 71, 73, 95-97, 109, 113]. Of these, seven studies were among adolescents and adults $[50,60,65,73,95,96$, 113], five studies were conducted among adolescents only in schools/communities (South Africa [46, 54, 97], Tanzania [48] and Mozambique [63]), three studies among university students in South Africa [41, 64, 66] and two studies among adult women [71, 109]. In seven studies, the proportion of boys that reported ever practising heterosexual insertive anal sex was higher than proportion of girls that reported ever engaging in receptive anal sex [41, 46, $48,54,65,66,73]$. For example, in Tanzania, 8.5 and 5.4\% of boys and girls reported ever having insertive or receptive anal sex, respectively [48]. In South Africa, 10.8 and $8.4 \%$ of male and female university students reported ever engaging in insertive or receptive anal sex, respectively [41]. In the three studies that were conducted among girls/ women only, the reported prevalence of receptive anal sex among adolescents and adults was $34.8 \%$ in Tanzania [50] and $7.7-11.3 \%$ in South Africa [95], and in a study from South Africa a prevalence of 1.5-1.9\% was reported among adult women [60].

In the remaining 11 general population studies that reported prevalence of ever practiced anal sex among boys/men and girls/women: three were among university students [35, 38, 68] and four studies each were among adolescents and adults in schools/community [39, 45, $52,78]$ or adolescents in schools $[47,55,56,80]$. The reported prevalence of ever practising anal sex among university students in Nigeria ranged between $0.3-4.4 \%$ $[35,68]$. In another similar study, $35.2 \%$ among university students in Zimbabwe, and $46.4 \%$ among university students in Nigeria reported ever practising in anal sex [38]. Studies that combined adolescent and adult populations reported prevalences between 4.3-34.8\% from Zambia, South Africa, Nigeria and Ethiopia [39, 45, 52, 78]. Studies amongst adolescents in schools/communities showed that the prevalence of ever practicing anal sex was $6.7-12.4 \%$ in Nigeria $[47,56], 2.4-3.8 \%$ in South Africa [80] and 6.4\% in Tanzania [55]. 
In key affected populations, the reported prevalence of ever practising receptive heterosexual anal sex in nine different studies among FSWs was $2.3-42.8 \%$ in Rwanda [36], Cameroun [110], Uganda [118], Kenya [74, 79, 89] and South Africa [57, 76, 106]; 42.0\% among male truck drivers in South Africa [75]; 25.4\% among men attending bars/ night clubs in South Africa [93]; 11.5\% [49], 2.4\% [82] and $0.4 \%$ [105] among women working in food and recreational facilities in Ghana, Tanzania and Kenya respectively. Other reported prevalences of anal sex were $3.3-17.1 \%$ among HIV positive men and women in Nigeria [42] and South Africa [61], 5.7-72.0\% among adult men and women in community/clinics in Nigeria [70] and Cameroun [114], $11.7-20.0 \%$ among adult men only in Nigeria [108] and Angola [107], and 13.4\% among adolescents and adults women in South Africa [117].

\section{Prevalence of heterosexual anal sex by other reporting periods}

Six key affected population studies reported specifically on insertive or receptive anal sex within the past 3 months $[44,53,83,84,90,91]$. Higher prevalences of insertive anal sex in the past 3 months were reported by men compared to receptive anal sex reported by women among key affected populations [44, 84]. Similarly, two key affected population studies in South Africa (one study each among HIV positive men and women [44] and adult men and women [84]) showed higher prevalences among men that reported practising insertive anal than women that engaged in receptive anal sex. Three other studies among HIV positive men and women in Kenya, South Africa and Zimbabwe described the prevalence of heterosexual anal sex in the past 3 months to be $18.0 \%$ [83], 7.7\% [53] and $4.8 \%$ [91] respectively.

Four studies among key affected populations presented prevalences of anal sex in the past month [67, 81, 87, 92]. One study compared prevalences of anal sex in the past month by method of data collection and found that women in food and recreational centres in Tanzania reported a higher prevalence of anal sex using daily diaries $(2.1 \%)$ to record their sexual behaviours compared to face-to-face interviews (1.4\%) [81]. The other two studies from South Africa reported the prevalence of insertive anal sex in the past month among men attending bars/night clubs and men patronising alcohol drinking points to be $15.0 \%$ [87] and $10.6 \%$ respectively [92]. In the same studies, $11.0 \%$ of women in bars/night clubs [87] and 6.9\% women at alcohol drinking points reported receiving anal sex in the past month [92]. Another study reported that 2.2\% of FSWs in South Africa, Uganda and republic of Benin received anal sex in the past month [67]. Other reporting periods used to describe prevalence for anal sex among key affected populations were past 12 months in 3 studies (two from Tanzania and Cote-d'ivoire) [111, 120, 121], and during the most recent sexual acts in 2 studies from Zimbabwe [37] and the Central African Republic [119].

Seven general population studies, including six from South Africa, reported on insertive or receptive anal sex in the past 3 months [51, 54, 58, 62, 77, 98, 99]. The range of reported prevalence of receptive anal sex in three studies among South African women was 5.6-20.3\% [62, 77, 98]. Two studies among adolescents and adults reported a prevalence of $2-3.0 \%[58,99]$. In the same country, a study showed that $1.1 \%$ of girls reported receptive anal sex while $7.4 \%$ of boys reported insertive anal sex during the same period [54]. A Kenyan study showed that $25.0 \%$ men reported insertive anal sex while $21.0 \%$ women reported receptive anal sex in the preceding 3 months [51].

Twelve studies used different reporting periods (past 12 months [52, 72, 115], past 6 months [59, 69, 94], past month $[85,86,88]$, during first sexual act [40] and last sexual act $[56,116])$. Within these reporting periods, the highest reported prevalence of anal sex was $57.1 \%$ among anal sex experienced Ethiopian high school students in the past 12 months [52], 9.2\% among South African young men and women in the past 6 months [59], 7.8\% of South African adult women in the past month [88] and 5.6\% of Nigerian boys during their last sexual act [56].

\section{Factors associated with engaging in anal sex}

Eight studies explored factors associated with practising heterosexual anal sex (Table 2). Two of the three studies that presented unadjusted estimates showed that the reported prevalence of heterosexual anal sex was associated with type of sexual relationship [54, 89]. A study amongst South African adolescents found that the prevalence of having ever practised heterosexual anal sex was higher among 'currently dating' girls (3.3\% vs $0 \%)$ and boys ( $15.6 \%$ vs $6.0 \%)$ than those with 'no dating partners' [54]. A similar result was also described in the same study among boys that reported prevalence of anal sex act in the past 3 months [54]. In Kenya the frequency of anal sex in past month among FSWs was higher among those with regular and casual partners than those with primary partner only [89]. In the same study, the frequency of condom use among FSWs was lower during anal sex than during vaginal sex (data not shown). Unlike the general gender pattern observed in other studies, women in Kenya reported a higher prevalence of heterosexual anal sex than men $(25.0 \%$ vs $16.0 \%)$ [51].

Five studies reported adjusted estimates on factors associated with reported anal sex [52, 66, 84, 87, 90]: A Kenyan study among FSWs showed that the odds of reporting heterosexual anal sex was about four times higher among those with current genital symptoms versus no genital symptoms, three times with inconsistent condom use during last sex compared to those reporting consistent condom use, two times with at least 5 years 
of sex compared to those with more than 5 years, six times with inconsistence condom use with casual partners than those that used condom, and higher number of sexual partners than those with lower number [90]. A study among FSWs in Rwanda found that inconsistent condom use with casual sex partners (adjusted odds ratio $(\mathrm{AOR})=5.9)$ and a higher number of sexual partners $(\mathrm{AOR}=4.3)$ were also identified as risk factors for reporting heterosexual anal sex [90]. In addition, the odds ratio for those with regular use of alcohol before sex was about three times associated with reporting anal sex than FSWs that did not regularly use alcohol before sex. A study among men and women attending bars/ night clubs in South Africa found the following factors to be associated with reported anal sex in the past month: younger age, having casual sexual partners compared to regular partner, having sex with only one sexual partner compared to having multiple recent sexual partners, and meeting their sexual partners in shebeens (alcohol drinking venues) in the past month [87].

Other risk factors associated with engaging heterosexual anal sex that were reported among men and women in the community and special treatment clinics in South Africa included the following [84]: never using condoms; previous transactional sex; cannabis use in the past 3 months; previously tested for HIV and being HIV positive. Being older, married or living with a partner and previous condomless vaginal intercourse reduced the risk of reporting anal sex. Factors associated with ever practising heterosexual anal sex among Ethiopian school boys and girls included younger age, being a boy, having a positive attitude towards anal sex, having low aspirations for college education, having low self-esteem, having a perception of peer engagement in anal sex and having an illiterate mother or father [52]. However, adolescents living with both parents were less likely to engage in anal sex [52]. In another Ethiopian study, reporting ever having had anal sex experience by university students was associated with enrolment in non-medical university faculties compared with students enrolled in a medical faculty [66]. In the same study, university students that had ever married were more likely to report previous anal sex experience than single students [66].

\section{Motivations for engaging in anal sex}

A study in Ethiopia described the motivations for engaging in anal sex among school-attending boys and girls aged 15-24 years [52]. The motivations included minimizing the risk of pregnancy (92.1\%), preserving virginity $(85.5 \%)$, minimising the risk of STIs $(82.9 \%)$, and minimising risk of acquiring HIV (77.6\%). Other motivations reported were desire by the sexual partner, increasing sexual pleasure, and self-preference for anal sex. Amongst the $57.0 \%$ who had reported in anal sex in the previous 12 months, $52.3 \%$ had received money or gifts for engaging in anal sex.

Four studies (two from Tanzania [103, 104], one from South Africa [100] and one multi-site study from Kenya, Tanzania and Uganda [102]) explored motivations for engaging in anal sex using qualitative research. Their findings showed that motivations differed between men and women (Table 1). Reasons mentioned by women were preserving their virginity, to promote a sexual relationship or to avoid a domestic quarrel, to prevent pregnancy, as an alternative during menstruation or during pregnancy or when there is evidence of a sexually transmitted infection, and in exchange for money [101, 102]. Motivations reported by men included adventure, influence from their peers, to avoid unwanted pregnancy, to enjoy enhanced sexual pleasure and to show sexual supremacy over women [104].

\section{Cultural meaning, interpretations and personal experiences of anal sex}

Twelve qualitative studies explored interpretations of anal sex (Table 1). Five qualitative studies reported on the culture of silence and reluctance to openly discuss heterosexual anal sex [90, 100, 103, 122, 123]. For example, a study in rural South Africa among men and women found that some participants considered heterosexual anal sex to be too sensitive for discussion and some even expressed shock, disappointment and threatened to abandon a focus group discussion when it was brought up for discussion by the facilitator [101]. In the same study, men were reported to be more willing to discuss anal sex than women. In another study in Kenya, men in two counties reported that they were reluctant to discuss anal sex among themselves as it was regarded as a cultural taboo to claim knowledge of, or practice, anal sex in their community [102].

Two studies (Rwanda and South Africa) reported that women, including FSWs, perceived anal sex as punishment, and they only engaged in it to avoid quarrel from their partners/clients and for financial benefits $[90,100]$. Other reasons mentioned by participants for engaging in anal sex included adventure, and coercion [100, 120, 124, 125]. There was some evidence of misunderstanding the definition of anal sex; for example, one South African study reported that participants in rural part of Soweto believed anal sex to mean "penile-vaginal penetration from behind" [100]. In several other studies, interviewees believed that anal sex is "foreign" to the African culture $[66,90,101]$ or that it is exclusively practiced by men who have sex with men [101]. Some believed anal sex is safer than penile-vaginal sex [120, 124].

Seven qualitative studies presented personal experiences of men and women about heterosexual anal sex [90, 100, 101, 103, 104, 120, 124]. Findings from three studies 
showed that men expressed more desire for anal sex than women as they often regarded the act as a sign of manhood, and women were reported not to be receptive to openly discussing or demanding anal sex [100, 103, 124]. Tanzanian and South African studies reported that both men and women sometimes used proxy names such as slang or colloquial terms to describe anal sex [101, 104]. A study among FSWs in Kigali reported extreme resentment towards clients who asked for anal sex as they regarded the practice to be uncomfortable, emotionally painful and associated with STIs and faecal and urinary incontinence [90]. However, some young women in Tanzania said that anal sex was more acceptable and enjoyable when performed with "jelly" lubricants [120].

\section{Assessment of quality of studies}

The detailed assessment of risk of bias are presented in Additional file 2: Table S3 and Additional file 1: Figures S3 and S6. Overall, 53 out of 94 quantitative studies assessed had low risk of bias in their methods: 51 of these described heterosexual anal sex $[40,52,54-57,59,60,62$, 64-67, 69-76, 79, 80, 82-84, 86-88, 90-93, 95, 96, 98, 99, 107-112, 115-121] while 24 studies described oral sex [40, 52, 54-60, 62, 64-67, 69-73, 131, 132, 135-137]. The majority of articles assessed to be low risk were from Southern and Eastern Africa. Most studies with a high risk of bias used convenience sampling techniques to recruit study participants, had unclear eligibility criteria, did not include operational definition of outcome measure in the methods, control for potential confounders and present prevalence of oral or anal sex by the reported sexual behaviour role, and gave no indication as to whether ethical approvals were obtained (data not shown - Additional file 2: Table S3). All the nine qualitative studies assessed had low risk of bias (Additional file 2: Table S4).

\section{Discussion}

This is the first systematic review of reported prevalence of oral and anal sex among adolescents and adults reporting heterosexual sex in SSA. The review showed a large range of prevalences for both behaviours. Generally, the range of prevalences were similar among key affected and general populations. However, reported prevalences of oral and anal sex among FSWs and university students tended to be higher than other population groups of adolescents and adults. In addition, reported prevalences of both oral and anal sex tended to be higher among males than females. Few studies reported the use of condoms or other barrier methods with oral and anal sex with a number of them reporting low or inconsistent condom use during oral and anal sex. Factors associated with these behaviours showed that those who engaged in oral and anal sex often also engaged in other high-risk activities such as having frequent and multiple sexual partners, illegal substance or alcohol use, and inconsistent condom use. Oral and anal sex are important modes of transmission for STIs, and these data are vital for understanding sexual behaviours in populations at high risk for STIs including HIV, oral and anal cancers.

Findings from three qualitative studies provided possible explanations for engaging in unprotected anal sex [100, $102,103]$ including that it was regarded as less risky than vaginal sex, and could prevent STIs including HIV. Anal sex was also associated with exchange of money or gifts among FSWs. Studies from USA also showed that the belief that oral sex is without health risk, and not regarding oral and anal sex as "having sex" might have accounted for low condom use [138, 139]. Qualitative research also illustrated a culture of silence in discussing anal sex, and many of those that discussed it expressed shock and disbelief that such sexual act existed within heterosexual relationships. This, combined with the belief by some boys/ men that performing heterosexual anal sex demonstrates a supremacy over girls/women, may further create a culture of secrecy, shame, and transgression. Indeed, women reported coercion for anal sex and a perception that men engaged in it to punish them. In such an environment, discussion about safety and condom use may be undermined, and strategies for STI control may be challenging. More research is needed to further understand motivations for and meaning of engaging in oral and anal sex in SSA, as well as opportunities and challenges for addressing violence, safety and STI/HIV risk.

The comparatively higher prevalences of oral and anal sex among some key affected populations compared to general populations in this review has also been widely reported in high income countries. Some studies among key affected populations suggested that these behaviours were associated with increased use of alcohol and substance abuse during sexual activity, increased frequency of sexual acts and multiple sexual partners [140-144]. Men who engaged in anal sex with FSWs were more likely to have consumed alcohol and be a frequent customer [140]. Apart from these reasons, it has also been reported that FSWs engaged more in oral and anal sex to satisfy their clients' requests and for financial gain $[140,145]$. This was corroborated by two qualitative studies in this review where FSWs reported economic gain as the main reason for engaging in anal sex [90, 103]. Adolescents in Ethiopia also reported receiving gifts or money for practicing oral and anal sex [52].

We observed high prevalences of oral and anal sex among university students, and this is similar to finding from studies in high-income countries. In the UK NATSAL survey, young people were more likely to report oral and anal sex than older adults, irrespective of gender [21]. The increased reporting of oral and anal sex among young people has been associated with changing perception of sexual activity among younger generation and the influence 
of social media including pornography amongst others [146-149]. An Australian study that was conducted among young people found that previous anal sex experience was associated with frequent use of pornography [149]. It will be important that adolescent health providers are aware that these behaviours are now being practiced by young people across the continent and education programmes will need to be tailored to addressing the risk associated with these behaviours and how these can be prevented.

Although routine testing for oropharyngeal and anal infections is recommended in high-income countries for sexually active MSM $[150,151]$, some argue that exclusion of sexually active women with history of receptive oral and anal sex from routine testing will lead to missed opportunities for early detection of STI and the prevention of onward transmission [150,151]. The cost-effectiveness of routine testing for asymptomatic pharyngeal and anal infection is unclear [151]. Routine testing strategy is not yet a feasible option for people reporting heterosexual oral and anal sex in SSA. However, raising awareness on the risk of STIs during unprotected oral and anal sex through information, education and counselling programmes could be a practicable strategy in the region. It is also imperative that policy makers in the region expand the concept of hetero-normative sexual act to include oral and anal sex.

The higher prevalence of reported oral and anal sex by males in this review should be interpreted within a context of reporting bias. Studies in SSA and other regions have shown that during self-reported sexual behaviour interviews, males tend to report a higher number of sexual partners, non-marital partners and concurrent relationships than females, and females may under-report numbers of sexual partnerships [152-154]. Reporting differences by gender may also vary according to the specific sexual behaviour. Available evidence from population studies in UK and USA showed that more men or boys reported receiving oral sex than women or girls in heterosexual relationship $[21,155]$. In the same report, more girls were reported to give oral sex than boys. Some researchers argued that gender differences in the reporting of sexual activity might be influenced by the perception of sexual pleasure, health risks and beliefs $[156,157]$. A qualitative study further showed that men preferred to receive oral sex from their partners than to give their partners because they perceived receiving oral sex to be less risky and giving oral sex to be a dirty and dangerous practice [158].

The strengths of this review are the range of prevalences across geographic sub-regions, populations and ages within SSA. However there are a number of limitations. There were very few population-based estimates of the oral and anal sex prevalence such as prevalences reported in the population-based studies in the UK and Australia [18, 21]. Instead, there was a wide range of prevalences of oral and anal sex observed in various population sub-groups which are unlikely to be generalizable. In addition, there were several methodological weaknesses in the studies reviewed including consistent operational definitions of oral and anal sex. Furthermore, studies also used different reporting periods making it challenging to pool and compare results across population sub-groups and settings in SSA.

In addition to reporting gender reporting bias discussed above, there is likely to be under-reporting of these sensitive behaviours due to social desirability bias, especially for heterosexual anal sex, since this practice is not well accepted in some communities [101, 102, 159]. Many studies were assessed as having a high-risk of bias and did not provide information on how their sample sizes were determined. Lastly, restricting our inclusion criteria to only published peer reviewed articles, limiting our search to seven databases and exclusion of MSM that also engaged in heterosexual oral and anal sex could have missed other studies that reported on oral and anal sex in the region.

\section{Conclusion}

In summary, oral and anal sex are commonly practiced among adolescents and adults reporting heterosexual sex in SSA, often without condom use. Future sexual reproductive health research investigating risks for STIs should incorporate questions on oral and anal sex using clear definitions of these behaviours. Well powered and rigorous population based study designs similar to studies in United Kingdom and Australia [18, 21, 160] are needed to understand population estimates of these behaviours, their associated morbidities, and changes in sexual behaviour trends over time. Researchers should also consider using qualitative research methods, complimentary tools such as pictures/drawings and other visual aids to elicit more accurate responses from participants [159]. Accurate data are needed to inform reproductive and sexual health policies, and information on oral and anal sex and their health risks should be included in information, education and counselling messages for both the key affected and general populations.

\section{Additional files}

Additional file 1: Figure S1. Prevalence of oral sex by sub-region. Figure S2. Prevalence of oral sex by population category. Figure S3. Prevalence of oral sex by risk of bias. Figure S4. Prevalence of anal sex by subregion. Figure S5 Prevalence of anal sex by population category. Figure S6. Prevalence of anal sex by risk of bias. (DOCX $122 \mathrm{~kb}$ )

Additional file 2: Table S1. Selected data from quantitative studies reporting on heterosexual oral and anal sex in sub-Saharan Africa by year of publication. Table S2. Reported condom use during penetrative heterosexual sex (oral, anal and vaginal). Table S3. Risk of bias assessment for quantitative studies. Table S4. Risk of bias assessment of qualitative studies. (XLSX $41 \mathrm{~kb})$ 


\section{Acknowledgements}

IMB received grant support from the University of Ibadan, Ibadan, Nigeria for his PhD programme at the London School of Hygiene and Tropical Medicine, London. SCF (MR/N023692/1 and MR/R010161/1) and KB (MR/ R010161/1) were funded by the UK Medical Research Council (MRC) and the UK Department for International Development (DFID) under the MRC/DFID Concordat agreement and is also part of the EDCTP2 programme supported by the European Union.

\section{Funding}

Not applicable.

\section{Availability of data and materials}

Interested parties can obtain all available data by contacting the corresponding author.

\section{Authors' contributions}

IMB participated in the design, conducted literature search, undertook screening of literature, extracted data and wrote the first draft. SK participated in screening of literature, verified data extraction and revised the manuscript. DWJ, SCF and KB participated in the design, supervised the literature search, data extraction and synthesis of results, including revision of the manuscript. All authors read and approved the final version of the manuscript.

\section{Ethics approval and consent to participate} Not applicable.

\section{Consent for publication}

Not applicable.

\section{Competing interests}

The authors declare that they have no competing interests.

\section{Publisher's Note}

Springer Nature remains neutral with regard to jurisdictional claims in published maps and institutional affiliations.

\section{Author details \\ ${ }^{1}$ Clinical Research Department, Faculty of Infectious and Tropical Diseases, London School of Hygiene and Tropical Medicine, Keppel St, London WC1E 7HT, UK. ${ }^{2}$ Obstetrics and Gynaecology Department, Faculty of Clinical Sciences, College of Medicine, University of Ibadan, Ibadan, Nigeria. ${ }^{3}$ Mwanza Intervention Trials Unit, National Institute for Medical Research, PO Box 11936, Mwanza, Tanzania. ${ }^{4}$ Department of Infectious Disease Epidemiology, Faculty of Epidemiology and Population Health, London School of Hygiene and Tropical Medicine, Keppel St, London WC1E 7HT, UK.}

Received: 10 May 2018 Accepted: 15 April 2019

Published online: 06 May 2019

\section{References}

1. van Liere G, Dukers-Muijrers N, Levels L, Hoebe C. High proportion of anorectal chlamydia trachomatis and Neisseria gonorrhoeae after routine universal urogenital and anorectal screening in women visiting the sexually transmitted infection clinic. Clin Infect Dis. 2017;64(12):1705-10.

2. Fernandez-Lopez C, Morales-Angulo C. Otorhinolaryngology manifestations secondary to oral sex. Acta Otorrinolaringol Esp. 2017;68(3):169-80.

3. Taylor S, Bunge E, Bakker M, Castellsague X. The incidence, clearance and persistence of non-cervical human papillomavirus infections: a systematic review of the literature. BMC Infect Dis. 2016;16:293.

4. Velicko I, Ploner A, Sparen P, Marions L, Herrmann B, Kuhlmann-Berenzon S. Sexual and testing behaviour associated with chlamydia trachomatis infection: a cohort study in an STI clinic in Sweden. BMJ Open. 2016;6(8):e011312.

5. Chan PA, Robinette A, Montgomery M, Almonte A, Cu-Uvin S, Lonks JR, Chapin KC, Kojic EM, Hardy EJ. Extragenital infections caused by chlamydia trachomatis and Neisseria gonorrhoeae: a review of the literature. Infect Dis Obstet Gynecol. 2016;2016:5758387.

6. Chancellor JA, loannides SJ, Elwood JM. Oral and oropharyngeal cancer and the role of sexual behaviour: a systematic review. Community Dent Oral Epidemiol. 2017;45(1):20-34. https://doi.org/10.1111/cdoe.12255
7. Assi R, Hashim PW, Reddy VB, Einarsdottir H, Longo WE. Sexually transmitted infections of the anus and rectum. World J Gastroenterol. 2014;20(41):15262-8,

8. O'Leary A, DiNenno E, Honeycutt A, Allaire B, Neuwahl S, Hicks K, Sansom S. Contribution of anal sex to HIV prevalence among heterosexuals: a modeling analysis. AIDS Behav. 2017;21(10):2895-2903. https://doi.org/10. 1007/s10461-016-1635-z

9. Patel P, Borkowf CB, Brooks JT, Lasry A, Lansky A, Mermin J. Estimating peract HIV transmission risk: a systematic review. Aids. 2014;28(10):1509-19.

10. Owen BN, Baggaley RF, Elmes J, Harvey A, Shubber Z, Butler AR, Silhol R, Anton P, Shacklett B, van der Straten A, Boily MC. What Proportion of Female Sex Workers Practise anal Intercourse and How Frequently? A Systematic Review and Meta-analysis. AIDS Behav. 2019. https://doi.org/10. 1007/s10461-019-02477-w. [Epub ahead of print]

11. Brown B, Blas MM, Cabral A, Carcamo C, Gravitt PE, Halsey N. Oral sex practices, oral human papillomavirus and correlations between oral and cervical human papillomavirus prevalence among female sex workers in Lima, Peru. Int J STD AIDS. 2011:22(11):655-8.

12. Cheng W, Tang W, Zhong F, Babu GR, Han Z, Qin F, Gao K, Mai H, Zhao Y, Liang C, et al. Consistently high unprotected anal intercourse (UAl) and factors correlated with UAl among men who have sex with men: implication of a serial cross-sectional study in Guangzhou, China. BMC Infect Dis. 2014;14:696.

13. Halperin DT. Heterosexual anal intercourse: prevalence, cultural factors, and HIV infection and other health risks, part I. AIDS Patient Care STDs. 1999;13(12):717-30.

14. Ma Q, Jiang J, Pan X, Cai G, Wang H, Zhou X, Jiang T, Chen L. Consistent condom use and its correlates among female sex workers at hair salons: a cross-sectional study in Zhejiang province, China. BMC Public Health. 2017; 17(1):910. https://doi.org/10.1186/s12889-12017-14891-12886.

15. Ramanathan S, Nagarajan K, Ramakrishnan L, Mainkar MK, Goswami P, Yadav D, Sen S, George B, Rachakulla H, Subramanian T, et al. Inconsistent condom use by male clients during anal intercourse with occasional and regular female sex workers (FSWs): survey findings from southern states of India. BMJ Open. 2014:4(11):e005166.

16. Marra E, Kroone N, Freriks E, van Dam CL, Alberts CJ, Hogewoning AA, Bruisten S, van Dijk A, Kroone MM, Waterboer T, et al. Vaginal and anal human papillomavirus infection and seropositivity among female sex workers in Amsterdam, the Netherlands: Prevalence, concordance and risk factors. J Infect. 2018;76(4):393-405. https://doi.org/10.1016/j.jinf.2017.1012. 1011 Epub 2017 Dec 1028.

17. Paz-Bailey G, Noble M, Salo K, Tregear SJ. Prevalence of HIV among U.S. female sex workers: systematic review and meta-analysis. AIDS Behav. 2016;20(10):2318-31.

18. Rissel C, Badcock PB, Smith AM, Richters J, de Visser RO, Grulich AE, Simpson $J M$. Heterosexual experience and recent heterosexual encounters among Australian adults: the second Australian study of health and relationships. Sex Health. 2014:11(5):416-26.

19. Gindi RM, Ghanem KG, Erbelding EJ. Increases in oral and anal sexual exposure among youth attending sexually transmitted diseases clinics in Baltimore, Maryland. J Adolesc Health. 2008;42(3):307-8.

20. de Visser RO, Smith AM, Rissel CE, Richters J, Grulich AE. Sex in Australia: heterosexual experience and recent heterosexual encounters among a representative sample of adults. Aust N Z J Public Health. 2003;27(2):146-54

21. Mercer $\mathrm{CH}$, Tanton C, Prah P, Erens B, Sonnenberg P, Clifton S, Macdowall W, Lewis R, Field N, Datta J, et al. Changes in sexual attitudes and lifestyles in Britain through the life course and over time: findings from the National Surveys of sexual attitudes and lifestyles (Natsal). Lancet. 2013;382(9907):1781-94.

22. Owen BN, Brock PM, Butler AR, Pickles M, Brisson M, Baggaley RF, Boily MC Prevalence and frequency of heterosexual anal intercourse among young people: a systematic review and meta-analysis. AIDS Behav. 2015;19(7):1338-60.

23. Rissel C, Badcock PB, Smith AM, Richters J, de Visser RO, Grulich AE, Simpson $J M$. Corrigendum to: heterosexual experience and recent heterosexual encounters among Australian adults: the second Australian study of health and relationships. Sex Health. 2015;12(6):568

24. Tarkang EE. Sexual risk behaviours of high school female learners in Mbonge subdivision of rural Cameroon. Pan Afr Med J. 2015;20:49.

25. Salih NA, Metaferia $H$, Reda AA, Biadgilign S. Premarital sexual activity among unmarried adolescents in northern Ethiopia: a cross-sectional study. Sex Reprod Healthc. 2015;6(1):9-13.

26. Naidoo S, Taylor M. HIV health literacy, sexual behaviour and selfreports of having tested for HIV among students. Afr J AIDS Res. 2015;14(2):107-15. 
27. Akinsoji AA, Olufunmilola AA, Idowu AA, Pius AO. Sexual and contraceptive practices among female undergraduates in a Nigerian tertiary institution. Ethiop J Health Sci. 2015;25(3):209-16.

28. van der Geugten J, van Meijel B, den Uyl MH, de Vries NK. Evaluation of a sexual and reproductive health education programme: students' knowledge, attitude and behaviour in Bolgatanga municipality, northern Ghana. Afr J Reprod Health. 2015;19(3):126-36

29. Muntean N, Kereta W, Mitchell KR. Addressing the sexual and reproductive health needs of young people in Ethiopia: an analysis of the current situation. Afr J Reprod Health. 2015;19(3):87-99.

30. Moher D, Liberati A, Tetzlaff J, Altman DG, The PRISMA Group. Preferred reporting items for systematic reviews and meta-analyses: the PRISMA statement. J Clin Epidemiol. 2009. https://doi.org/10.1016/jjclinepi200906005.

31. Stroup DF, Berlin JA, Morton SC, Olkin I, Williamson GD, Rennie D, Moher D, Becker BJ, Sipe TA, Thacker SB. Meta-analysis of observational studies in epidemiology: a proposal for reporting. Meta-analysis of observational studies in epidemiology (MOOSE) group. JAMA. 2000;283(15):2008-12.

32. Morhason-Bello I, Francis S, Kabakama S, Watson-Jones D. A systematic review on oral and anal sexual behaviour among heterosexually active adolescents and adults in sub-Saharan Africa. In: PROSPERO: CRD42015025311; 2015. Available from http://www.crd.york.ac.uk/ PROSPERO/DisplayPDF.php?ID=CRD42015025311. Accessed 3 May 2019.

33. Downes MJ, Brennan ML, Williams HC, Dean RS. Development of a critical appraisal tool to assess the quality of cross-sectional studies (AXIS). BMJ Open. 2016:6:e011458

34. Critical appraisal skills programme (CASP) qualitative research checklist 2017. Available at: https://casp-uk.net/wp-content/uploads/2018/01/CASPQualitative-Checklist-2018.pdf. Accessed 3 May 2019.

35. Soyinka F. Sexual behavior among university students in Nigera. Arch Sex Behav. 1979;8(1):15-26.

36. Van de Perre P, Clumeck N, Carael M, Nzabihimana E, Robert-Guroff M, De Mol P, Freyens P, Butzler JP, Gallo RC, Kanyamupira JB. Female prostitutes: a risk group for infection with human T-cell lymphotropic virus type III. Lancet. 1985;2(8454):524-7.

37. Wilson D, Chiroro P, Lavelle S, Mutero C. Sex worker, client sex behaviour and condom use in Harare, Zimbabwe. AIDS Care. 1989;1(3):269-80.

38. Akande A. AIDS-related beliefs and behaviours of students: evidence from two countries (Zimbabwe and Nigeria). Int J Adolesc Youth. 1994;4(34):285-303.

39. Feldman DA, O'Hara P, Baboo KS, Chitalu NW, Lu Y. HIV prevention among Zambian adolescents: developing a value utilization/norm change model. Soc Sci Med. 1997:44(4):455-68.

40. Matasha E, Ntembelea T, Mayaud P, et al. Sexual and reproductive health among primary and secondary school pupils in Mwanza, Tanzania: need for intervention. AIDS Care. 1998;10(5):571-82.

41. Nicholas LJ. The association between religiosity, sexual fantasy, participation in sexual acts, sexual enjoyment, exposure, and reaction to sexual materials among black south Africans. J Sex Marital Ther. 2004;30(1):37-42.

42. Nnoruka EN, Ezeoke AC. Evaluation of syphilis in patients with HIV infection in Nigeria. Trop Med Int Health. 2005;10(1):58-64.

43. Okafor II, Obi SN. Sexual risk behaviour among undergraduate students in Enugu, Nigeria. J Obstet Gynaecol. 2005;25(6):592-5.

44. Cornman DH, Kiene SM, Christie S, Fisher WA, Shuper PA, Pillay S, Friedland $\mathrm{GH}$, Thomas CM, Lodge L, Fisher JD. Clinic-based intervention reduces unprotected sexual behavior among HIV-infected patients in KwaZulu-Natal, South Africa: results of a pilot study. J Acquir Immune Defic Syndr. 2008; 48(5):553-6.

45. Morhason-Bello IO, Oladokun A, Enakpene CA, Fabamwo AO, Obisesan KA, Ojengbede OA. Sexual behaviour of in-school adolescents in Ibadan, southWest Nigeria. Afr J Reprod Health. 2008;12(2):89-97.

46. Plüddemann A, Flisher AJ, Mathews C, Carney T, Lombard C. Adolescent methamphetamine use and sexual risk behaviour in secondary school students in Cape Town, South Africa. Drug Alcohol Rev. 2008;27(6):687-92.

47. Bamidele JO, Abodunrin OL, Adebimpe WO. Sexual behavior and risk of HIV/AIDS among adolescents in public secondary schools in Osogbo, Osun state, Nigeria. Int J Adolesc Med Health. 2009;2009(21):387-94.

48. Kazaura MR, Masatu MC. Sexual practices among unmarried adolescents in Tanzania. BMC Public Health. 2009;9:373.

49. Opoku B. Contraceptive use among 'at-risk' women in a metropolitan area in Ghana. Acta Obstet Gynecol Scand. 2010;89(8):1105-7.

50. Maswanya ES, Moji K, Aoyagi K, Takemoto T. Sexual behavior and condom use in female students in Dar-es-Salaam, Tanzania: differences by steady and casual partners. East Afr J Public Health. 2011;8(2):69-76.
51. Chege W, Pals SL, McLellan-Lemal E, Shinde S, Nyambura M, Otieno FO, Gust DA, Chen RT, Thomas T. Baseline findings of an HIV incidence cohort study to prepare for future HIV prevention clinical trials in Kisumu, Kenya. J Infect Dev Ctries. 2012;15(6):870-80

52. Cherie A, Berhane Y. Oral and anal sex practices among high school youth in Addis Ababa, Ethiopia. BMC Public Health. 2012;12:5.

53. Peltzer K. Correlates of HIV infection among people visiting public HIV counseling and testing clinics in Mpumalanga, South Africa. Afr Health Sci. 2012;12(1):8-16.

54. Gevers A, Mathews C, Cupp P, Russell M, Jewkes R. Illegal yet developmentally normative: a descriptive analysis of young, urban adolescents' dating and sexual behaviour in Cape Town, South Africa. BMC Int Health Hum Rights. 2013;13:31.

55. Kakoko DC. Reported heterosexual intercourse and related behaviours among primary school pupils in Kinondoni district, Dar es Salaam, Tanzania. Cult Health Sex. 2013;15(2):235-45.

56. Folayan MO, Odetoyinbo M, Brown B, Harrison A. Differences in sexual behaviour and sexual practices of adolescents in Nigeria based on sex and self-reported HIV status. Reprod Health. 2014;11:83.

57. Dunkle KL, Beksinska ME, Rees VH, Ballard RC, Htun Y, Wilson ML. Risk factors for HIV infection among sex workers in Johannesburg, South Africa. Int J STD AIDS. 2005;16(3):256-61.

58. Skoler-Karpoff S, Ramjee G, Ahmed K, Altini L, Plagianos MG, Friedland B, Govender S, De Kock A, Cassim N, Palanee T, et al. Efficacy of Carraguard for prevention of HIV infection in women in South Africa: a randomised, double-blind, placebo-controlled trial. Lancet. 2008;372(9654):1977-87.

59. Andersson KM, Van Niekerk RM, Niccolai LM, Mlungwana ON, Holdsworth I, Bogoshi M, McIntyre JA, Gray GE, Vardas E. Sexual risk behaviour of the first cohort undergoing screening for enrollment into phase I/II HIV vaccine trials in South Africa. Int J STD AIDS. 2009;20(2):95-101.

60. Nel A, Louw C, Hellstrom E, Braunstein SL, Treadwell I, Marais M, de Villiers M, Hugo J, Paschke I, Andersen C, et al. HIV prevalence and incidence among sexually active females in two districts of South Africa to determine microbicide trial feasibility. PloS One. 2011;6(8):e21528.

61. van Loggerenberg F, Dieter AA, Sobieszczyk ME, Werner L, Grobler A, Mlisana K, Team CAIS. HIV prevention in high-risk women in South Africa: condom use and the need for change. PLoS One. 2012;7(2):e30669.

62. Gaffoor Z, Wand H, Daniels B, Ramjee G. High risk sexual behaviors are associated with sexual violence among a cohort of women in Durban, South Africa. BMC Res Notes. 2013;6:532.

63. Cossa HA, Gloyd S, Vaz RG, Folgosa E, Simbine E, Diniz M, Kreiss JK. Syphilis and HIV infection among displaced pregnant women in rural Mozambique. Int J STD AIDS. 1994;5(2):117-23.

64. Sallah ED, Grunitzky-Bekele M, Bassabi K, Dodzro K, Sadzo A, Balogou AK, Grunitzky EK, Gaudreau L. The sexual behavior, knowledge and attitudes towards aids and sexually transmitted diseases of students at the University of Benin (Togo). Cahiers Sante. 1999;9(2):101-9.

65. Operario D, Pettifor A, Cluver L, MacPhail C, Rees H. Prevalence of parenta death among young people in South Africa and risk for HIV infection. J Acquir Immune Defic Syndr. 2007;44(1):93-8.

66. Ambaw F, Mossie A, Gobena T. Sexual practices and their development pattern among Jimma university students. Ethiopian J Health Sci. 2010;20(3):159-67.

67. Guedou FA, Damme L, Mirembe F, Solomon S, Becker M, Deese J, Crucitti T, Alary M. Intermediate vaginal flora is associated with HIV prevalence as strongly as bacterial vaginosis in a cross-sectional study of participants screened for a randomised controlled trial. Sex Transm Infect. 2012;88(7):545-51.

68. Asekun-Olarinmoye OS, Asekun-Olarinmoye EO, Adebimpe WO, Omisore AG. Effect of mass media and internet on sexual behavior of undergraduates in Osogbo metropolis, Southwestern Nigeria. Adolesc Health Med Ther. 2014;5:15-23.

69. Dubbink JH, van der Eem L, Mclntyre JA, Mbambazela N, Jobson GA, Ouburg S, Morre SA, Struthers HE, Peters RP. Sexual behaviour of women in rural South Africa: a descriptive study. BMC Public Health. 2016;16:557.

70. Lawan UM, Amole GT, Shuaib MJ. Sexual health of prison inmates: a case study of Kano central prison, north western Nigeria. Afr J Reprod Health. 2016;20(1):98-103.

71. Dareng EO, Adebamowo SN, Eseyin OR, Odutola MK, Pharoah PP, Adebamowo CA. Test-retest reliability of self-reported sexual behavior history in urbanized Nigerian women. Front Public Health. 2017;5:172. https://doi.org/10.3389/fpubh.2017.00172 eCollection 02017. 
72. Davey DJ, Farley E, Gomba Y, Coates T, Myer L. Sexual risk during pregnancy and postpartum periods among HIV-infected and -uninfected South African women: Implications for primary and secondary HIV prevention interventions. PLoS One. 2018;13(3):e0192982.

73. Ybarra M, Price-Feeney M, Mwaba K. Prevalence and correlates of anal sex among secondary school students in Cape Town, South Africa. AIDS Care. 2018;30(7):821-9.

74. Fonck K, Kaul R, Kimani J, et al. A randomized, placebo-controlled trial of monthly azithromycin prophylaxis to prevent sexually transmitted infections and HIV-1 in Kenyan sex workers: study design and baseline findings. Int J STD AIDS. 2000;11(12):804-11.

75. Ramjee G, Gouws E. Prevalence of HIV among truck drivers visiting sex workers in KwaZulu-Natal, South Africa. Sex Transm Dis. 2002;29(1):44-9.

76. Van Damme L, Ramjee G, Alary M, Vuylsteke B, Chandeying V, Rees H, Sirivongrangson P, Mukenge-Tshibaka L, Ettiègne-Traoré V, Uaheowitchai C, et al. Effectiveness of COL-1492, a nonoxynol-9 vaginal gel, on HIV-1 transmission in female sex workers: a randomised controlled trial. Lancet. 2002;360(9338):971-7.

77. Kalichman SC, Simbayi LC. Sexual assault history and risks for sexually transmitted infections among women in an African township in Cape Town, South Africa. AIDS Care. 2004;16(6):681-9.

78. Mpofu E, Flisher AJ, Bility K, Onya H, Lombard C. Sexual partners in a rural south African setting. AIDS Behav. 2006;10(4):399-404.

79. Schwandt M, Morris C, Ferguson A, Ngugi E, Moses S. Anal and dry sex in commercial sex work, and relation to risk for sexually transmitted infections and HIV in Meru, Kenya. Sex Transm Infect. 2006;82(5):392-6.

80. Jaspan HB, Flisher AJ, Myer L, Mathews C, Seebregts C, Berwick JR, Wood R, Bekker LG. Brief report: methods for collecting sexual behaviour information from south African adolescents--a comparison of paper versus personal digital assistant questionnaires. J Adolesc. 2007;30(2):353-9.

81. Allen CF, Lees SS, Desmond NA, et al. Validity of coital diaries in a feasibility study for the Microbicides Development Programme tria among women at high risk of HIV/AIDS in Mwanza, Tanzania. Sex Transm Infect. 2007;83(6):490-6.

82. Watson-Jones D, Weiss H, Rusizoka M, Baisley K, Mugeye K, Changalucha J, Everett D, Balira R, Knight L, Ross D, Hayes RJ. Risk factors for herpes simplex virus type 2 and HIV among women at high risk in northwestern Tanzania: preparing for an HSV-2 intervention trial. J Acquir Immune Defic Syndr. 2007:46(5):631-42

83. Grijsen ML, Graham SM, Mwangome M, et al. Screening for genital and anorectal sexually transmitted infections in HIV prevention trials in Africa. Sex Transm Infect. 2008:84(5):364-70.

84. Kalichman SC, Simbayi LC, Cain D, Jooste S. Heterosexual anal intercourse among community and clinical settings in Cape Town, South Africa. Sex Transm Infect. 2009;85(6):411-5.

85. Abdool Karim Q, Abdool Karim SS, Frohlich JA, Grobler AC, Baxter C, Mansoor LE, Kharsany AB, Sibeko S, Mlisana KP, Omar Z, et al. Effectiveness and safety of tenofovir gel, an antiretroviral microbicide, for the prevention of HIV infection in women. Science. 2010;329(5996):1168-74.

86. Karim QA, Kharsany AB, Frohlich JA, Werner L, Mashego M, Mlotshwa M, Madlala BT, Ntombela F, Abdool Karim SS. Stabilizing HIV prevalence masks high HIV incidence rates amongst rural and urban women in KwaZuluNatal, South Africa. Int J Epidemiol. 2011;40(4):922-30.

87. Kalichman SC, Pinkerton SD, Carey MP, et al. Heterosexual anal intercourse and HIV infection risks in the context of alcohol serving venues, Cape Town, South Africa. BMC Public Health. 2011;11:807.

88. Mensch BSHP, Abbott S, Rankin J, Littlefield S, Ahmed K, Cassim N, Patel SRG, Palanee T, Mierzwa S, Skoler-Karpoff S. Assessing the reporting of adherence and sexual activity in a simulated microbicide trial in South Africa: an interview mode experiment using a placebo gel. AIDS Behav. 2011;15(2):407-21.

89. Priddy FH, Wakasiaka S, Hoang TD, et al. Anal sex, vaginal practices, and HIV incidence in female sex workers in urban Kenya: implications for the development of intravaginal HIV prevention methods. AIDS Res Hum Retrovir. 2011;27(10):1067-72.

90. Veldhuijzen NJ, Ingabire C, Luchters S, Bosire W, Braunstein S, Chersich M, van de Wijgert J. Anal intercourse among female sex workers in East Africa is associated with other high-risk behaviours for HIV. Sex Health. 2011;8(2):251-4.

91. Venkatesh KK, de Bruyn G, Mayer KH, et al. Changes in sexual risk behavior before and after HIV seroconversion in southern African women enrolled in a HIV prevention trial. J Acquir Immune Defic Syndr. 2011;57(5):435-41.
92. Cain D, Pare V, Kalichman SC, Harel O, Mthembu J, Carey MP, Carey KB, Mehlomakulu V, Simbayi LC, Mwaba K. HIV risks associated with patronizing alcohol serving establishments in South African townships, Cape Town. Prev Sci. 2012;13(2):627-34.

93. Scott-Sheldon LA, Carey MP, Carey KB, et al. HIV testing is associated with increased knowledge and reductions in sexual risk behaviours among men in Cape Town, South Africa. Afr J AIDS Res. 2013;12(4):195-201.

94. Gray GE, Metch B, Churchyard G, Mlisana K, Nchabeleng M, Allen M, Moodie Z, Kublin J, Bekker LG, HVTN 503 team. Does participation in an HIV vaccine efficacy trial affect risk behaviour in South Africa? Vaccine. 2013;31(16):2089-96.

95. Jemmott JB, 3rd, , Jemmott LS, O'Leary A, Ngwane Z, Icard LD, Heeren GA, Mtose X, Carty C: Cluster-randomized controlled trial of an HIV/sexually transmitted infection risk-reduction intervention for south African men. Am J Public Health 2014, 104(3):467-473.

96. Guffey MB, Richardson B, Husnik M, Makanani B, Chilongozi D, Yu E, Ramjee G, Mgodi N, Gomez K, Hillier SL, et al. HPTN 035 phase II/Ilb randomised safety and effectiveness study of the vaginal microbicides BufferGel and 0 . 5\% PRO 2000 for the prevention of sexually transmitted infections in women. Sex Transm Infect. 2014;90(5):363-9.

97. Thurston IB, Dietrich J, Bogart LM, Otwombe KN, Sikkema KJ, Nkala B, Gray GE. Correlates of sexual risk among sexual minority and heterosexual south African youths. Am J Public Health. 2014;104(7):1265-9.

98. Noguchi LM, Richardson BA, Baeten JM, Hillier SL, Balkus JE, Chirenje ZM, Bunge K, Ramjee G, Nair G, Palanee-Phillips T, et al. Risk of HIV-1 acquisition among women who use diff erent types of injectable progestin contraception in South Africa: a prospective cohort study. Lancet HIV. 2015;2(7):e279-87.

99. Palanee-Phillips T, Schwartz K, Brown ER, Govender V, Mgodi N, Kiweewa FM, Nair G, Mhlanga F, Siva S, Bekker LG, et al. Characteristics of women enrolled into a randomized clinical trial of Dapivirine vaginal ring for HIV-1 prevention. PLoS One. 2015;10(6):e0128857.

100. Stadler JJ, Delany S, Mntambo M. Sexual coercion and sexual desire: ambivalent meanings of heterosexual anal sex in Soweto, South Africa. AIDS Care. 2007;19(10):1189-93.

101. Ndinda C, Chimbwete C, McGrath N, Pool R. Perceptions of anal sex in rural South Africa. Cult Health Sex. 2008;10(2):205-12.

102. Duby Z, Colvin C. Conceptualizations of heterosexual anal sex and HIV risk in five east African communities. J Sex Res. 2014;51(8):863-73.

103. Beckham SW, Shembilu CR, Winch PJ, Beyrer C, Kerrigan DL. If you have children, you have responsibilities': motherhood, sex work and HIV in southern Tanzania. Cult Health Sex. 2015;17(2):165-79.

104. Wamoyi J, Mongi A, Sally M, Kakoko D, Shamba D, Geubbels E, Kapiga S. A qualitative study of discourses on heterosexual anal sexual practice among key, and general populations in Tanzania: implications for HIV prevention. BMC Public Health. 2015:15:417.

105. Katsivo MN, Muthami LN. Social characteristics and sexual behaviour of women at high risk of HIV infection in a town in Central Province of Kenya. Arch AIDS Res. 1991;5(1-2):25-7.

106. Karim SSA, Ramjee G. Anal sex and HIV transmission in women. Am J Public Health. 1998:88(8):1265-6.

107. Bing EG, Cheng KG, Ortiz DJ, Ovalle-Bahamon RE, Ernesto F, Weiss RE, Boyer CB. Evaluation of a prevention intervention to reduce HIV risk among Angolan soldiers. AIDS Behav. 2008;12(3):384-95.

108. Adoga MP, Banwat EB, Forbi JC, Nimzing L, Pam CR, Gyar SD, Agabi YA Agwale SM. Human immunodeficiency virus, hepatitis B virus and hepatitis $C$ virus: sero-prevalence, co-infection and risk factors among prison inmates in Nasarawa state, Nigeria. J Infect Dev Ctries. 2009;3(7):539-47.

109. van der Elst EM, Okuku HS, Nakamya P, Muhaari A, Davies A, McClelland RS, Price MA, Smith AD, Graham SM, Sanders EJ. Is audio computer-assisted self-interview (ACASI) useful in risk behaviour assessment of female and male sex workers, Mombasa, Kenya? PloS One. 2009;4(5):e5340.

110. Essomba EN, Kollo B, Kouoh Ngambi M, Owona Manga L, Mbunya S, Bita Fouda A, Dissongo Jl, Mikendeffo D, Lehman L. Sex risk behaviour and prevalence of HIV of sex workers in Douala at 2011. Mali Med. 2013;2:24-8

111. Lambdin BH, Bruce RD, Chang O, Nyandindi C, Sabuni N, Zamudio-Haas S McCurdy S, Masao F, Ivo Y, Msami A, et al. Identifying programmatic gaps: inequities in harm reduction service utilization among male and female drug users in Dar es Salaam, Tanzania. PLoS One. 2013;8(6):e67062.

112. Githuka G, Hladik W, Mwalili S, Cherutich P, Muthui M, Gitonga J, Maina WK, Kim AA. Populations at increased risk for HIV infection in Kenya: results from a national population-based household survey, 2012. (special issue: Kenya AIDS Indicator survey 2012.). J Acquir Immune Defic Syndr. 2014;66(Suppl. 1):S46-56. 
113. Anyanwu PE, Fulton J. Knowledge and perception of young adults in Nigeria on effectiveness of condom use in prevention of sexually transmitted infections. Int J Adolesc Med Health. 2015. https://doi.org/10.1515/ijamh-2015-0050.

114. Luma HN, Eloumou SAFB, Atemlefeh FE, Malongue A, Temfack E, Lekpa FK Donfack-Sontsa O, Ndip L, Ditah IC. Anorectal pathology amongst HIV infected patients attending the Douala General Hospital: a cross-sectional study. Int J STD AIDS. 2016;0:1-8. https://doi.org/10.1177/0956462416650817.

115. McLellan-Lemal E, Gust DA, Gvetadze R, Furtado M, Otieno FO, Desai M, Zeh C, Samandari T, Nyagol B, Makanga EM. Characteristics of women screened for a contraceptive intravaginal ring study in Kisumu, Kenya, 2014. Res J Womens Health. 2016;3:1-23.

116. Teasdale CA, Abrams EJ, Chiasson M, Justman J, Blanchard AK, Jones HE. Sexual risk and intravaginal practice behavior changes during pregnancy. Arch Sex Behav. 2016. https://doi.org/10.1007/s10508-016-0818-z.

117. Giorgio M, Townsend L, Zembe Y, Cheyip M, Guttmacher S, Kapadia F, Mathews C. The relationship between social support, HIV Serostatus, and perceived likelihood of being HIV positive among self-settled female, foreign migrants in Cape Town, South Africa. J Immigr Minor Health. 2017; 19(4):883-90.

118. Hladik W, Baughman AL, Serwadda D, Tappero JW, Kwezi R, Nakato ND, Barker J. Burden and characteristics of HIV infection among female sex workers in Kampala, Uganda - a respondent-driven sampling survey. BMC Public Health. 2017:17(1):565

119. Longo JD, Simaleko MM, Diemer HS, Gresenguet G, Brucker G, Belec L. Risk factors for HIV infection among female sex workers in Bangui, Central African Republic. PLoS One. 2017;12(11):e0187654.

120. Shayo EH, Kalinga AA, Senkoro KP, Msovela J, Mgina EJ, Shija AE, Materu G, Kilima SP, Mboera LEG, Massaga JJ. Prevalence and risk factors associated with female anal sex in the context of HIV/AIDS in the selected districts of Tanzania. BMC Res Notes. 2017;10:140.

121. Maheu-Giroux M, Baral S, Vesga JF, Diouf D, Diabate S, Alary M, Abo K, Boily MC. Anal intercourse among female sex Workers in Cote d'Ivoire: prevalence, determinants, and model-based estimates of the populationlevel impact on HIV transmission. Am J Epidemiol. 2018;187(2):287-97.

122. Mavhu W, Langhaug L, Manyonga B, Power R, Cowan F. What is 'sex' exactly? Using cognitive interviewing to improve the validity of sexual behaviour reporting among young people in rural Zimbabwe. Cult Health Sex. 2008;10(6):573-85. https://doi.org/10.1080/13691050801999071.

123. Duby Z, Hartmann M, Montgomery ET, Colvin CJ, Mensch B, Straten A Sexual scripting of heterosexual penile-anal intercourse amongst participants in an HIV prevention trial in South Africa, Uganda and Zimbabwe. Cult Health Sex. 2016;18(1):30-44.

124. Mtenga S, Shamba D, Wamoyi J, Kakoko D, Haafkens J, Mongi A, Kapiga S, Geubbels E. How long-distance truck drivers and villagers in rural southeastern Tanzania think about heterosexual anal sex: a qualitative study. Sex Transm Infect. 2015;91(8):576-80.

125. Mazeingia YT, Olijjira L, Dessie $Y$. Anal sexual experience and HIV risk awareness among female sex workers in Dire Dawa, eastern Ethiopia. Glob Health Res Policy. 2017:2:27. https://doi.org/10.1186/s41256-41017-40047-41256.

126. Tengia-Kessy A, Msamanga Gl, Moshiro CS. Assessment of behavioural risk factors associated with HIV infection among youth in Moshi rural district, Tanzania. East Afr Med J. 1998;75(9):528-32.

127. Fawole OI, Ajayi IO, Babalola TD, Oni AA, Asuzu MC. Socio-demographic characteristics and sexual behaviour of adolescents attending the STC, UCH, Ibadan: a 5 year review. West Afr J Med. 1999;18(3):165-9.

128. Okesola AO, Fawole Ol. Prevalence of human papilloma virus genital infections in sexually transmitted diseases clinic attendees in Ibadan. West Afr J Med. 2000;19(3):195-9.

129. Vogt SL, Gravitt PE, Martinson NA, Hoffmann J, D'Souza G. Concordant Oralgenital HPV infection in South Africa couples: evidence for transmission. Front Oncol. 2013;3:303.

130. Davidson CL, Richter KL, Van der Linde M, Coetsee J, Boy SC. Prevalence of oral and oropharyngeal human papillomavirus in a sample of south African men: a pilot study. S Afr Med J. 2014;104(5):358-61.

131. Kerwin JT, Thornton RL, Foley SL. Prevalence of and factors associated with oral sex among rural and urban Malawian men. Int J Sexual Health. 2014;26(1):66-77.

132. Meque I, Dube K, Feldblum PJ, Clements AC, Zango A, Cumbe F, Chen PL, Ferro JJ, van de Wijgert JH. Prevalence, incidence and determinants of herpes simplex virus type 2 infection among HIV-seronegative women at high-risk of HIV infection: a prospective study in Beira, Mozambique. PloS One. 2014;9(2):e89705
133. Gathece LW. Prevalence of oral sex and wet kissing among female sex workers in two areas of Nairobi, Kenya. Afr J Oral Health Sci. 2000;1(1):17-8.

134. Mbulawa ZZA, Johnson LF, Marais DJ, Coetzee D, Williamson AL. Risk factors for oral human papillomavirus in heterosexual couples in an African setting. J Infect. 2014;68:185-9.

135. Animasahun VJ, Sholeye OO, Oduwole AD. Promoting the sexual and reproductive health of adolescent females in ljebu-Ode, southwest, Nigeria: a study of sexual risk-taking. Int J Adolesc Med Health. 2016;29(6):09.

136. Arulogun OS, Ogbu IA, Dipeolu IO. Influence of internet exposure on sexual behaviour of young persons in an urban district of Southwest Nigeria. Pan Afr Med J. 2016;25:261

137. Chikandiwa A, Pisa PT, Chersich MF, Muller EE, Mayaud P, Delany-Moretlwe S. Oropharyngeal HPV infection: prevalence and sampling methods among HIV-infected men in South Africa. Int J STD AIDS. 2018;29(8):776-80.

138. Sanders SA, Reinisch JM. Would you say you "had sex" if...? JAMA. 1999; 281(3):275-7.

139. Sanders SA, Hill BJ, Yarber WL, Graham CA, Crosby RA, Milhausen RR. Misclassification bias: diversity in conceptualisations about having 'had sex'. Sex Health. 2010;7(1):31-4.

140. Wong WCW, Lin Yim Y, Lynn H. Sexually Transmitted Infections Among Female Sex Workers in Hong Kong: The Role of Migration Status, J Travel Med. 2011;18(1):1-7. https://doi.org/10.1111/j.1708-8305.2010.00453.x

141. Lim RB, Wong ML, Tan PH, Govender M. Heterosexual men who patronise entertainment establishments versus brothels in an Asian urban setting - which group practises riskier sexual behaviours? BMC Public Health. 2015;15:777.

142. World Health Organisation. Alcohol use and sexual risk behaviour: a crosscultural study in eight countries. 2005. Available from: https://www.who.int/ substance_abuse/publications/alcohol_sexual_risk_crosscultural.pdf. Accessed 3 May 2019

143. Mao YX, Xiao CC, Wang T, Li SY, Yan H. One-night-stand behavior and associated factors among young men who have sex with men in Wuhan, China. Zhonghua Liu Xing Bing Xue Za Zhi. 2017;38(6):746-9.

144. Calsyn DA, Hatch-Maillette MA, Meade CS, Tross S, Campbell AN, Beadnell B. Gender differences in heterosexual anal sex practices among women and men in substance abuse treatment. AIDS Behav. 2013;17(7):2450-8.

145. Beattie TS, Bradley JE, Vanta UD, Lowndes CM, Alary M. Vulnerability reassessed: the changing face of sex work in Guntur district, Andhra Pradesh. AIDS Care. 2013;25(3):378-84.

146. Lewis R, Tanton C, Mercer CH, Mitchell KR, Palmer M, Macdowall W, Wellings K. Heterosexual practices among young people in Britain: evidence from three national surveys of sexual attitudes and lifestyles. J Adolesc Health. 2017;61(6):694-702.

147. Pizzol D, Bertoldo A, Foresta C. Adolescents and web porn: a new era of sexuality. Int J Adolesc Med Health. 2016;28(2):169-73.

148. Smith LW, Liu B, Degenhardt L, Richters J, Patton G, Wand H, Cross D, Hocking JS, Skinner SR, Cooper S, Lumby C, Kaldor JM, Guy R. Is sexual content in new media linked to sexual risk behaviour in young people? A systematic review and meta-analysis. Sex Health. 2016. https://doi.org/10. 1071/SH16037 [Epub ahead of print].

149. Lim MSC, Agius PA, Carrotte ER, Vella AM, Hellard ME. Young Australians' use of pornography and associations with sexual risk behaviours. Aust NZ J Public Health. 2017:41:438-43.

150. Centers for Disease Control and Prevention. Sexually transmitted diseases treatment guidelines. 2015. Available from: https://www.cdc.gov/std/ tg2015/default.htm. Accessed 20 Nov 2018.

151. Dukers-Muijrers NH, Schachter J, van Liere GA, Wolffs PF, Hoebe CJ. What is needed to guide testing for anorectal and pharyngeal Chlamydia trachomatis and Neisseria gonorrhoeae in women and men? Evidence and opinion. BMC Infect Dis. 2015;15:533.

152. Curtis SL, Sutherland EG. Measuring sexual behaviour in the era of HIV/AIDS: the experience of demographic and health surveys and similar enquiries. Sex Transm Infect. 2004;80(2):22-7.

153. Plummer M, Ross D, Wight D, Changalucha J, Mshana G, Wamoyi J, Todd J, Anemona A, Mosha F, Obasi A, et al. "A bit more truthful": the validity of adolescent sexual behaviour data collected in rural northern Tanzania using five methods. Sex Transm Infect. 2004;80(2):45-56.

154. Doyle AM, Plummer ML, Weiss HA, Changalucha J, Watson-Jones D, Hayes RJ, Ross DA. Concurrency and other sexual partnership patterns reported in a survey of young people in rural northern Tanzania. PLoS One. 2017;12(8):e0182567. 
155. Child Trends Databank. Oral sex behaviors among teens. 2015. Available from: https://www.childtrends.org/wp-content/uploads/2015/11/indicator_ 1446940280.638.pdf. Accessed 3 May 2019.

156. Lefkowitz ES, Vasilenko SA, Leavitt CE. Oral vs. vaginal sex experiences and consequences among first-year college students. Arch Sex Behav. 2016; 45(2):329-37.

157. Brady SS, Halpern-Felsher BL. Adolescents' reported consequences of having oral sex versus vaginal sex. Pediatrics. 2007;119(2):229-36.

158. Lewis R, Marston C. Oral sex, young people, and gendered narratives of reciprocity. J Sex Res. 2016;53(7):776-87.

159. Duby Z, Hartmann M, Mahaka I, Munaiwa O, Nabukeera J, Vilakazi N Mthembu F, Colvin CJ, Mensch B, van der Straten A. Lost in translation: language, terminology, and understanding of penile-anal intercourse in an HIV prevention trial in South Africa, Uganda, and Zimbabwe. J Sex Res. 2016:53(9):1096-106

160. Mercer CH, Wellings K, Johnson AM. What's new about Natsal-3? Sex Transm Infect. 2014;90(2):80-1.

Ready to submit your research? Choose BMC and benefit from:

- fast, convenient online submission

- thorough peer review by experienced researchers in your field

- rapid publication on acceptance

- support for research data, including large and complex data types

- gold Open Access which fosters wider collaboration and increased citations

- maximum visibility for your research: over $100 \mathrm{M}$ website views per year

At BMC, research is always in progress.

Learn more biomedcentral.com/submissions 